This is a postprint version of: Díaz-Faes, A.A., \& Bordons, M. (2014). Acknowledgements in scientific publications: presence in Spanish science and text patterns across disciplines. Journal of the Association for Information Science and Technology, 65 (9), 1834-1849. DOI: 10.1002/asi.23081.

The final publication is available at Wiley: http://onlinelibrary.wiley.com/doi/10.1002/asi.23081/abstract

\title{
Acknowledgements in scientific publications: presence in Spanish science and text patterns across disciplines
}

\author{
Adrián A. Díaz-Faes*, María Bordons \\ IEDCYT, Center for Human and Social Sciences (CCHS), Spanish National Research Council (CSIC), \\ Albasanz 26-28, 28037 Madrid,Spain.E-mail:adrian.arias@cchs.csic.es,maria.bordons@cchs.csic.es.
}

\begin{abstract}
The acknowledgements in scientific publications are an important feature in the scholarly communication process. This research analyzes funding acknowledgement presence in scientific publications and introduces a novel approach for discovering text patterns by discipline in the acknowledgement section of papers. First, the presence of acknowledgements in 38,257 Englishwritten papers published by Spain in 2010 is studied by subject area on the basis of the 'Funding Acknowledgement' information available in the Web of Science database. Funding acknowledgements are present in two thirds of Spanish articles with significant differences by subject area, number of authors, impact factor of journals and -in one specific area - by the basic/applied nature of research. Secondly, the existence of specific acknowledgement patterns in English-written papers of Spanish researchers in four selected subject categories (Cardiac \& Cardiovascular Systems, Economics, Evolutionary Biology and Statistics \& Probability) is explored through a combination of text mining and multivariate analyses. 'Peer interactive communication' predominates in the more theoretical or social-oriented fields (Statistics \& Probability and Economics), while the recognition of technical assistance is more common in experimental research (Evolutionary Biology) and the mention of potential 'conflicts of interest' emerges forcefully in the clinical field (Cardiac \& Cardiovascular Systems). The systematic
\end{abstract}

\footnotetext{
* Corresponding author: adrian.arias@.cchs.csic.es. Tel. +34 916022895
} 
This is a postprint version of: Díaz-Faes, A.A., \& Bordons, M. (2014). Acknowledgements in scientific publications: presence in Spanish science and text patterns across disciplines. Journal of the Association for Information Science and Technology, 65 (9), 1834-1849. DOI: 10.1002/asi.23081.

The final publication is available at Wiley: http://onlinelibrary.wiley.com/doi/10.1002/asi.23081/abstract

inclusion of structured data about acknowledgements in journal articles and bibliographic databases would have a positive impact on the study of collaboration practices in science.

\section{Introduction}

Research is an increasingly collaborative activity. A series of benefits drawn from collaboration, such as the sharing of knowledge, skills and techniques; the cross-fertilization of ideas; the division of labor or the increased motivation derived from human interaction, have been mentioned in the literature. Collaboration enables scientists to address increasingly complex research problems and obtain greater effectiveness in the development of research (Bordons \& Gómez, 2000). From a bibliometric point of view, the upward trend observed in co-authorship rates throughout the past decades in most scientific fields is a reflection of the mounting role of collaboration in science. In parallel, acknowledgements, which may be considered a measure of "sub-authorship collaboration" (Patel, 1973; Heffner, 1981), have also intensified their presence in scientific publications.

Acknowledgements are an important feature in scholarly communication since they are used to recognize some special contributions to research that do not qualify for authorship status but may well have a significant bearing on the final results of research (Kassirer \& Angell, 1991). As stated by Cronin (1995), an acknowledgement is a voluntary act that appears following an implicit code of professional conduct. It has become a constitutive feature of the academic journal article throughout the $20^{\text {th }}$ century, as well as a potentially rich source of insight into sub-authorship collaboration in science.

Acknowledgements may be made for different reasons, but they are usually expressions of gratitude concerning different types of support received by researchers. Two general types of support were described by Patel (1973), who distinguishes between technical support including, among other tasks, collecting data, processing data, operating laboratory machinery and performing 
This is a postprint version of: Díaz-Faes, A.A., \& Bordons, M. (2014). Acknowledgements in scientific publications: presence in Spanish science and text patterns across disciplines. Journal of the Association for

Information Science and Technology, 65 (9), 1834-1849. DOI: 10.1002/asi.23081.

The final publication is available at Wiley: http://onlinelibrary.wiley.com/doi/10.1002/asi.23081/abstract

statistical analyses; and theoretical support, such as reading, editing and contributing comments to a draft paper. A more detailed typology was suggested by Cronin and colleagues, who have conducted different studies on the function, frequency and evolution of acknowledgements in journal papers for various disciplines: Information Science \& Library Science (Cronin, 1991; Cronin, McKenzie, \& Stiffer, 1992); History, Philosophy, Psychology and Sociology (Cronin, McKenzie, \& Rubio, 1993; Cronin, Shaw, \& La Barre, 2003); and Chemistry (Cronin, Shaw, \& La Barre, 2004). As a result of a survey conducted to analyze formal acknowledgements of the papers appeared in JASIS from 1970 to 1990, Cronin identified six acknowledgement categories: paymaster, moral support, dogsbody, technical, prime mover and trusted assessor (Cronin, 1991, 1995). According to this author, 'paymaster' covers the recognition of grants or fellowships; 'moral support' shows credit for the provision of access to institutional facilities; 'dogsbody' refers to the support from colleagues in routine work such as bibliographic checking, data collection or analyses; 'technical' embraces advice on statistical techniques, computer programming and comparable tasks; 'prime mover' is reserved for individuals who have been influential in stimulating or encouraging the study; and 'trusted assessor' is for those who have helped with their ideas, suggestions or insights to shape the work. In more recent studies on Psychology and Philosophy (Cronin et al., 2003) and Chemistry (Cronin et al., 2004) acknowledgements were classified as moral, financial, editorial, instrumental/technical and conceptual/cognitive. The conceptual category, which was initially described by McCain (1991) as "peer interactive communication" (PIC), is particularly interesting. According to this author, PIC includes different contributions such as providing specific information or making specific suggestions, providing critical comments on manuscripts, proffering thanks for advice and discussion, and proffering thanks for inspiration. Since conceptual support implies an intellectual debt, it is especially relevant, to such an extent that some researchers consider it should deemed at least as valuable as citations (Edge, 1979; Cronin, McKenzie, Rubio, \& Weaver-Wozniak, 1993). 
This is a postprint version of: Díaz-Faes, A.A., \& Bordons, M. (2014). Acknowledgements in scientific publications: presence in Spanish science and text patterns across disciplines. Journal of the Association for Information Science and Technology, 65 (9), 1834-1849. DOI: 10.1002/asi.23081.

The final publication is available at Wiley: http://onlinelibrary.wiley.com/doi/10.1002/asi.23081/abstract

In assessing the research performance of scientists, measures based on productivity (number of publications) and impact (citations) play the most relevant role in the prevailing reward system of science. The need for acknowledgements to be also taken into account in what has been dubbed as the "reward triangle" was put forward by Cronin \& Weaver (1995), who argued that acknowledgements have a social, cognitive and instrumental meaning which should be studied. As stated critically by these authors, "the most trivial citation counts for more than the most sincere acknowledgement". But both, citations and acknowledgements, describe interaction and influence and should be studied as important features of the scholarly communication process.

Until recently, it was very difficult to carry out studies about acknowledgements (see for instance, Giles \& Council, 2004) because this information was not available in bibliographic databases. However, the Web of Science (WoS) has been including funding acknowledgement data since August 2008. This recent development in the WoS database opens up new possibilities for data mining and the analysis of the information contained in the acknowledgement section of papers (Rigby, 2011).

Acknowledgement data can be used for a variety of purposes in science studies, which range from the study of the interaction among scientists from a sociological standpoint to their uses in research evaluation and funding policy issues. Since many funding bodies mandate to be acknowledged in the papers resulting from the research made with their support, the analysis of the acknowledgement information can be useful to track research output and assess influence for any funding body or specific grant/research program and to identify the strategic scope of a funding agency (Rigby, 2011, 2013). Some studies have analyzed these trends and identified the most acknowledged entities by category (Lewison \& Markusova, 2010; Giles \& Council, 2004) and/or by country (Wang \& Shapira, 2011; Wang, Liu, Ding, \& Wang, 2012). It has been suggested that funding income might be an indicator of research quality (Gillet, 1991) because research funding entities generally apply some form of peer review to grant applications. This claim is consistent 
This is a postprint version of: Díaz-Faes, A.A., \& Bordons, M. (2014). Acknowledgements in scientific publications: presence in Spanish science and text patterns across disciplines. Journal of the Association for Information Science and Technology, 65 (9), 1834-1849. DOI: 10.1002/asi.23081.

The final publication is available at Wiley: http://onlinelibrary.wiley.com/doi/10.1002/asi.23081/abstract

with the results of Costas and van Leeuwen (2012), who analyzed scientific publications covered by the WoS in 2009 and described a higher impact for publications with funding acknowledgements when compared to the remaining papers. The impact of grant-funded research was also found to be higher than that of the rest of research in a study dealing with core journals in Library \& Information Science (Zhao, 2010) and in a work focusing on US research (Levitt, 2011). Although there is some research suggesting that the impact of research increases with the number of funding sources (Lewison \& Dawson, 1998), no clear relationship between both variables has been observed in other studies (Rigby, 2011, 2013).

In recent decades, an increase in the use of acknowledgements has been described in different disciplines such as Chemistry (Cronin et al., 2004), or Psychology and Philosophy (Cronin et al., 2003). Interestingly, differences by discipline in the frequency of acknowledgements (Costas \& van Leeuwen, 2012) and in the prevailing type of support acknowledged have been observed (Cronin et al., 2004). Acknowledgements seem to be more frequent in hard sciences, but more elaborated in Humanities and Social Sciences (Salager-Meyer, Alcaraz-Ariza, Luzardo-Briceño, \& Jabbour, 2011). While financial support emerges as the prevailing type in some disciplines such as Chemistry (Cronin et al., 2004) and Psychology (Cronin et al., 2003), the conceptual type is the most common in other fields, as is the case of Philosophy (Cronin et al., 2003). Moreover, the context of publication (for example, the geographic origin of articles and language) also bears an influence on the frequency and content of acknowledgements, which seem to be longer and appear more frequently in Anglo-American journals, maybe because acknowledgements have not yet become such a highly institutionalized practice in the non-Anglo-American context (SalagerMeyer, Alcaraz-Ariza, \& Pabón-Bervesí, 2009).

Against this backdrop, our research aims to increase our knowledge about the presence and role of acknowledgements in scientific publications. First, the analysis of funding acknowledgement presence in English-written papers published by Spanish researchers is carried 
This is a postprint version of: Díaz-Faes, A.A., \& Bordons, M. (2014). Acknowledgements in scientific publications: presence in Spanish science and text patterns across disciplines. Journal of the Association for Information Science and Technology, 65 (9), 1834-1849. DOI: 10.1002/asi.23081.

The final publication is available at Wiley: http://onlinelibrary.wiley.com/doi/10.1002/asi.23081/abstract

out with special emphasis in differences by subject area. The study focuses on papers written in English because acknowledgements need to be in English to be captured and processed by Thomson Reuters ${ }^{1}$. Secondly, the existence of specific acknowledgement patterns by discipline is explored in four disciplines. Although the inclusion of acknowledgement data in bibliographic databases represents an important step forward, their use remains complicated as they include unstructured information (natural language text). The study of the content of acknowledgements in previous works is generally addressed by visual inspection and the classification of records according to an acknowledgement typology based on motivation, as the one described by Cronin (1995). An interesting exception is the paper by Costas and van Leeuwen (2012) in which PIC is identified by means of a search strategy in the funding acknowledgement information available in WoS records. In this study, we introduce a novel approach which explores the usefulness of textual data analysis (Lebart \& Salem, 1994; Lebart, Salem, \& Bécue, 2000) to identify acknowledgement patterns by discipline.

\section{Objectives}

The acknowledgement section of WoS papers written in English by Spain-based researchers is analyzed in this study with two different and complementary purposes: firstly, to increase our knowledge about funding acknowledgement presence by subject area; and secondly, to discover specific acknowledgement patterns by discipline.

With respect to the first objective, a variety of questions, such as the following, is addressed: Are there inter-area differences in the presence of acknowledgements in papers? Is there any evidence establishing the higher quality of funded research? Does funded research include a higher number of authors? Are there differences between basic and applied research in their propensity to acknowledge funding? Does the behavior towards acknowledgement practices of Spanish researchers resemble that of the international scientific community in their corresponding fields? 
This is a postprint version of: Díaz-Faes, A.A., \& Bordons, M. (2014). Acknowledgements in scientific publications: presence in Spanish science and text patterns across disciplines. Journal of the Association for Information Science and Technology, 65 (9), 1834-1849. DOI: 10.1002/asi.23081.

The final publication is available at Wiley: http://onlinelibrary.wiley.com/doi/10.1002/asi.23081/abstract

The second objective of the paper is to assess the possibility of obtaining acknowledgement patterns by discipline. Since the acknowledgement section includes natural language text, textual data analysis and multivariate techniques are used to characterize four disciplines based on the type of information included in the acknowledgement section of papers (analysis of lexical profile). It is interesting to point out that the acknowledgement section of papers includes funding data, but also sub-authorship information. Therefore, both types of information contribute to define the final disciplinary pattern. Differences between disciplines in their acknowledgement patterns are expected due to divergences in their culture norms and funding, instrumentation and teamwork requirements.

Many studies on collaboration in science use only coauthorship-based indicators to analyze collaborative research. However, Melin and Persson (1996) suggest that when we reduce collaboration to co-authorship we are running the risk of neglecting some collaborative activity. According to Laudel (2002), half of the collaborative research practices are overlooked by the classical bibliometric indicator. In this sense, the inclusion of acknowledgements information in the WoS breaks new ground to study collaboration in science from a wider perspective.

\section{Data and methods}

The methodological aspects of the paper are organized into three different information blocks. First, a description of data sources and the structure of the acknowledgement information in the WoS database is provided. Then, one different information block is obtained for each of the two approaches adopted for the study of the FA section: analysis of FA presence by subject area in Spanish output and textual analysis of acknowledgements in selected disciplines.

\section{Data sources}

Scientific papers published in English by Spain-based researchers in 2010 were downloaded 
This is a postprint version of: Díaz-Faes, A.A., \& Bordons, M. (2014). Acknowledgements in scientific publications: presence in Spanish science and text patterns across disciplines. Journal of the Association for

Information Science and Technology, 65 (9), 1834-1849. DOI: 10.1002/asi.23081.

The final publication is available at Wiley: http://onlinelibrary.wiley.com/doi/10.1002/asi.23081/abstract

from the WoS database in March 2012. The study focuses on citable items, which include original articles and reviews (hereafter referred to as 'papers'). The WoS database includes three sections of information on 'Funding Acknowledgement'² (FA): 'Funding Agency' (FO) contains the names of the agencies that support the research; 'Grant Number' (FG) provides project identification numbers, if any; and 'Funding text' (FT) contains the full text included by the authors in the acknowledgement section of the paper. An example of the funding acknowledgement data included in a paper in WoS is shown below (Table 1).

Table 1. Example of WoS funding acknowledgement data.

\begin{tabular}{lll}
\hline Funding Agency & Grant Number & Funding Text \\
\hline Instituto de Salud Carlos III, Madrid, & G03/078 & The study was supported by a grant from the Instituto \\
Spain & & $\begin{array}{l}\text { de Salud Carlos III, Madrid, Spain (grant code: } \\
\text { G03/078). Two research grants from Lund University }\end{array}$ \\
Lund University Hospital & Hospital and The Swedish Heart-Lung Foundation are \\
acknowledged. The authors would like to thank
\end{tabular}

In this article, we have worked with the information in the FT section of the WoS records, although we shall refer to it as 'FA' for the sake of clarity, since it was considered a clearer abbreviation for 'Funding Acknowledgement'. Note that acknowledgements are only collected in the WoS when they include funding information, but for all such entries all acknowledgement types included by the authors (not only those of the funding type) are collected. This means that our results on the presence of acknowledgements are referred specifically to funding, but we can explore sub-authorship patterns when data on the latter have been collected along with any funding information. We consider that the set of acknowledged funding records provides a representative substratum for the study of acknowledgement patterns by discipline.

Analysis of FA presence by subject area

The presence of FA in Spanish scientific publications is analyzed for the total country and by 
This is a postprint version of: Díaz-Faes, A.A., \& Bordons, M. (2014). Acknowledgements in scientific publications: presence in Spanish science and text patterns across disciplines. Journal of the Association for Information Science and Technology, 65 (9), 1834-1849. DOI: 10.1002/asi.23081.

The final publication is available at Wiley: http://onlinelibrary.wiley.com/doi/10.1002/asi.23081/abstract

subject area. Publications were assigned to disciplines following the WoS's classification of journals into subject categories. A total of 243 subject categories ${ }^{3}$ were grouped into 10 subject areas: Agriculture, Biology \& Environment; Biomedicine; Chemistry; Clinical Medicine; Engineering \& Technology; Humanities; Mathematics; Multidisciplinary; Physics; and Social Sciences.

A study of the relationship between FA presence and different variables, namely, the prestige of the publication journal, the degree of collaboration in papers and the basic/applied nature of research, was undertaken using the following indicators:

a) Journal prestige: papers published in first quartile journals (Q1) (top 25\% journals in the impact factor journal ranking) within each Journal Citation Reports subject category were identified to explore whether research published in Q1 journals showed a greater presence of FA.

b) Collaboration: the average number of authors per paper depending of whether the research was funded or not was studied.

c) Basic/applied nature of research: a classification of journals into four research levels ranging from 1 (most applied level) to 4 (most basic level) was used. The research level was assigned to individual journals on the basis of both expert review and patterns of journal-to-journal citation, in a way that each journal refers mainly to itself and to other journals in the same level or one level more basic. This classification was described by the company CHI Research/Computer Horizons Inc. (Noma, 1986; Narin, Pinski, \& Gee, 1976), which now operates as ipIQ. The average research level of papers depending on whether the research was funded or not was analyzed.

SPSS v.19 was used for the statistical analysis of data. Differences in the presence of FA by genre were studied by applying the $\chi^{2}$ test. Mann-Whitney's U test for non-parametric distributions was performed to explore differences in the average number of authors and in the average research 
This is a postprint version of: Díaz-Faes, A.A., \& Bordons, M. (2014). Acknowledgements in scientific publications: presence in Spanish science and text patterns across disciplines. Journal of the Association for

Information Science and Technology, 65 (9), 1834-1849. DOI: 10.1002/asi.23081.

The final publication is available at Wiley: http://onlinelibrary.wiley.com/doi/10.1002/asi.23081/abstract

level of papers according to FA presence (funded vs. non-funded papers). The relationship between the percentage of papers with FA in total journals and in Q1 journals was studied by subject area and subject category through Spearman's rho coefficient. The $\alpha$ level was fixed at $5 \%$.

\section{Analysis of textual patterns in four subject categories}

An in-depth analysis of four subject categories was conducted to characterize them according to the specific role of acknowledgements in each discipline. It is interesting to remark that both funding acknowledgement and sub-authorship collaboration data contribute to define the specific pattern of each category. Our aim was to extract knowledge embedded within the text. Since knowledge is expressed by words, a lexicometric analysis establishing a statistical relationship among lexical units was carried out. The subject categories selected for these purposes were the following: Cardiac \& Cardiovascular Systems, Economics, Evolutionary Biology and Statistics \& Probability (Table 2). They differ in their subject area of assignment, their theoretical/experimental orientation, and the basic/applied nature of their research, as measured through the research level indicator. These features were taken into account under the assumption that they may have an influence on the type of information to be included in the acknowledgement section of papers.

Table 2. Number of papers, presence of funding acknowledgements and average research level by subject category.

\begin{tabular}{lllccc}
\hline Subject category (WoS) & Subject Area & Broad area & $\begin{array}{c}\text { No. Papers in } \\
\text { WoS (2010) }\end{array}$ & $\begin{array}{c}\text { \% Papers } \\
\text { with FA }\end{array}$ & $\begin{array}{c}\text { Research level } \\
\text { (mean) }\end{array}$ \\
\hline Cardiac \& & Clinical Medicine & Health Sciences & 380 & $52.4 \%$ & 1.9 \\
Cardiovascular Systems & Social Sciences & Social Sciences & 546 & $12.8 \%$ & 2.8 \\
Economics & Agric., Biol. \& Env. & Natural Sciences & 271 & $88.5 \%$ & 4 \\
Evolutionary Biology & Exact Sciences & 294 & $75.5 \%$ & 2.6 \\
Statistics \& Probability & Mathematics & Exact & \\
\hline
\end{tabular}

In order to analyze the text appearing in the acknowledgement section of papers, textual data 
This is a postprint version of: Díaz-Faes, A.A., \& Bordons, M. (2014). Acknowledgements in scientific publications: presence in Spanish science and text patterns across disciplines. Journal of the Association for

Information Science and Technology, 65 (9), 1834-1849. DOI: 10.1002/asi.23081.

The final publication is available at Wiley: http://onlinelibrary.wiley.com/doi/10.1002/asi.23081/abstract

analysis was used (Lebart \& Salem, 1994; Lebart et al., 2000) and the frequency of occurrence of words was obtained. The corpus was segmented into minimal units for frequency calculation. The processing of textual data and the building of a lexical table was carried out by means of Lexico 3 (Lamalle, Martínez, Fleury, \& Salem, 2003). Since the software used considers variant forms of a given term as different terms, a previous text normalization was performed in order to prevent such problems. Accordingly, orthographic variations were unified: for example, spelling variations (center vs. centre); variant forms due to slashes, hyphens (co-author vs. coauthor) or punctuation marks (WHO or W.H.O.); and variations due to the use of capital letters (capital letters were only maintained in personal and institutional names). Acronyms were also revised as a potential distorting element (for example, FIS or Fondo de Investigaciones Sanitarias). Stop-words, i.e., words with little semantic content which do not provide useful information for the analysis, were removed (articles, pronouns, prepositions, conjunctions, auxiliary and modal verbs). Mid level "lemmatization" was applied (Bolasco, 1992), which means that the different inflected forms of a word were grouped to its lemma thus enabling them to be analyzed as a single item: verbs into their infinitive form (e.g., “'supports', 'supported', 'supporting' $\rightarrow$ 'support') and nouns into their singular form. In addition, words with a different lemma but with equivalent semantic content were grouped together (for example, 'JAE', 'FPU' and 'FPI' were grouped together under the 'fellowship' entry since they are acronyms for different programs of fellowship grants in Spain). Finally, personal or institutional names and project numbers have not been taken into account for the analysis because the focus of this paper is on identifying acknowledgement patterns and finding out possible sub-authorship inferences. As a matter of fact, we are more interested in the 'reasons' underlying the acknowledgements than in the identification of the individuals and institutions acknowledged. A threshold of 10 occurrences in the corpus was set in order to select the words to be included in the lexical table. Different frequency thresholds were tested and the position of words and subject categories in the factorial planes remained quite stable. A lexical table is a cross 
This is a postprint version of: Díaz-Faes, A.A., \& Bordons, M. (2014). Acknowledgements in scientific publications: presence in Spanish science and text patterns across disciplines. Journal of the Association for

Information Science and Technology, 65 (9), 1834-1849. DOI: 10.1002/asi.23081.

The final publication is available at Wiley: http://onlinelibrary.wiley.com/doi/10.1002/asi.23081/abstract

tabulation formed by the words and the four selected subject categories, and the number of cooccurrences for each category, so that cell $(\mathbf{i}, \mathbf{j})$ contains the number of occurrences for the word $\mathbf{i}$ in the FA of the category $\mathbf{j}$. The matrix obtained has the form $\mathrm{X}_{93 \times 4}$ (93 words and 4 subject categories).

Correspondence Analysis (CA) is a multivariate technique for displaying the rows and columns of a two-way contingency table as points in a low-dimensional space, so that the positions of the row and column points are consistent with their associations in the lexical table. This method was proposed by Benzécri (1973) and reviewed by Escofier and Pagès (1992) and Lebart and Salem (1994), among others. In our study, CA was applied to a data matrix of words and subject categories to find two vector spaces, one representing the words and the other the categories. For distances between two points corresponding to words and two points corresponding to subject categories to make sense, row-profiles and column-profiles tables are calculated to show the relative frequency distributions of a line of the table (row or column) regarding to its total marginal.

Taking the profiles for the construction of the points, the differences between the distributions of acknowledgements in the text samples are measured by $\chi^{2}$ distances (which are weighted Euclidean distances between normalized rows with weights inversely proportional to the square roots of the column totals) associated to the matrix into orthogonal factors. The proximity between subject categories represents similarities between them, i.e., if two categories are very close in the projection, they are characterized by the same words. The distances between words and subject categories should be interpreted only in barycentric terms. In general, the points near the origin are underrepresented (Berthier \& Bouroche, 1975). Note that the weight assigned to the lines of the matrix is inversely proportional to its total marginal. Therefore, words with the highest frequency rates are placed near the origin while those with lower frequency rates will move away from the center of gravity of the axes. Taking into account that the WoS includes FA when papers include 
This is a postprint version of: Díaz-Faes, A.A., \& Bordons, M. (2014). Acknowledgements in scientific publications: presence in Spanish science and text patterns across disciplines. Journal of the Association for Information Science and Technology, 65 (9), 1834-1849. DOI: 10.1002/asi.23081.

The final publication is available at Wiley: http://onlinelibrary.wiley.com/doi/10.1002/asi.23081/abstract

information about their funding, words with the highest frequency ranking are expected to be related to funding and, therefore, lower frequency terms will be the ones relevant to explore different patterns in sub-authorship information.

For the interpretation of CA seeking maximum inertia plans, the number of factors required to represent the information properly is a question that has to be addressed. The importance of each axis is measured through a percentage of inertia (i.e., variance) represented by an eigenvalue $(\lambda)$, which measures the inertia of each of the principal axes, i.e., ${ }^{\lambda} / \sum^{\lambda_{a}}$ measures the inertia absorbed by the first axis and $\sqrt[\left(\lambda_{2}+\lambda_{2}\right)]{\Sigma \lambda_{2}}$ measures the inertia absorbed by the plane $1-2$. Total inertia is equal to the sum of all principal inertias $\left(\lambda_{1}, \lambda_{2}, \lambda_{3} \ldots \lambda_{\mathrm{n}}\right)$. Besides that, several measures are important to obtain a correct interpretation. The relative contribution of a factor to the element is the relative variability of the variable (subject category) accounted by that factor. These relative contributions tell us how the information is distributed across the axes. In addition, for a point (row or column) on a factorial plane, the quality of representation can be defined by adding the two relative contributions of these factors to the element. Only words and subject categories with a high quality of representation can be properly interpreted. In this study the quality of representation is rated on a scale ranging from 0 to 1000 points. Words with a quality of representation below 400 points are not represented in factorial planes. Besides, Ward's Hierarchical Clustering method was applied using factor scores to identify acknowledgement patterns of subject categories based on similar lexical features. The statistical analysis was run using MultBiplot software (Vicente-Villardón, 2010). A flow diagram of the process is displayed in Figure 1. 
This is a postprint version of: Díaz-Faes, A.A., \& Bordons, M. (2014). Acknowledgements in scientific publications: presence in Spanish science and text patterns across disciplines. Journal of the Association for Information Science and Technology, 65 (9), 1834-1849. DOI: 10.1002/asi.23081.

The final publication is available at Wiley: http://onlinelibrary.wiley.com/doi/10.1002/asi.23081/abstract

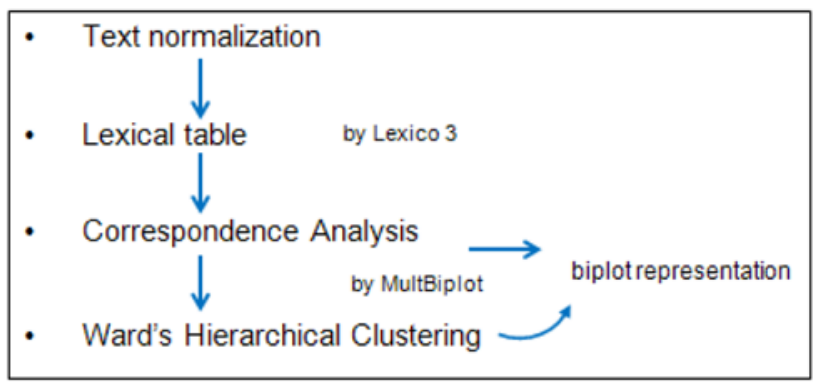

Fig. 1. Stages in the textual analysis of acknowledgements.

\section{Results}

The scientific papers published in English by Spain-based researchers in 2010 total 43,360 publications, of which 27,774 (64\%) present FA data. Our analyses are based on 'citable items' $(38,257)$, with FA being present in $72.6 \%$ of them (Table 3). Differences in FA presence by genre are observed in Table 3.

Table 3. FA presence by genre.

\begin{tabular}{lccc}
\hline \multirow{2}{*}{ Genre } & Without & With & Total \\
& FA & FA & \\
\hline Articles & $8,113(23.4 \%)$ & $26,577(76.6 \%)$ & 34,690 \\
Reviews & $642(35 \%)$ & $1,191(65 \%)$ & 1,833 \\
Proceedings papers & $1,728(99.7 \%)$ & $6(0.3 \%)$ & 1,734 \\
\hline Total citable items & $10,483(27.4 \%)$ & $27,774(72.6 \%)$ & 38,257 \\
\hline$\chi^{2}=4636.6 ; p<0.01$. Percentages in rows. & &
\end{tabular}

The results below are presented in two distinct sections devoted to (a) the analysis of FA presence by subject area and (b) the analysis of textual patterns by subject category.

a) Analysis of FA presence by subject area

The presence of FA in English-written papers published by Spain varies by subject area (Table 4). It is low in Humanities (20\%) and Social Sciences (28\%) and intermediate in Clinical Medicine 
This is a postprint version of: Díaz-Faes, A.A., \& Bordons, M. (2014). Acknowledgements in scientific publications: presence in Spanish science and text patterns across disciplines. Journal of the Association for Information Science and Technology, 65 (9), 1834-1849. DOI: 10.1002/asi.23081.

The final publication is available at Wiley: http://onlinelibrary.wiley.com/doi/10.1002/asi.23081/abstract

(59\%), whereas it stands above $73 \%$ in the remaining areas. Physics and Chemistry obtain the highest percentages of publications with FA (above 81\%). Figure 2 shows the distribution of the category share of papers with FA by subject area, which is quite similar across experimental areas (e.g., Physics, Chemistry, Mathematics) and presents a higher level of dispersion in Engineering \& Technology (from $34 \%$ in Transportation to $87 \%$ in Mathematical \& Computational Biology) and Biomedicine (from $61 \%$ to $95 \%$ ). The case of the Multidisciplinary area should be analyzed with care, since only two subject categories make up the whole area. Clinical Medicine shows a more dispersed pattern in FA frequency which ranges from Surgery (21\%) to Toxicology (83\%), while Social Sciences presents a right-skewed distribution, from Sociology and International Relations $(0 \%)$ to Psychology, Biological (85\%). Lastly, Humanities also show s a right-skewed distribution, from Linguistics (8\%) to Archaeology (52\%).

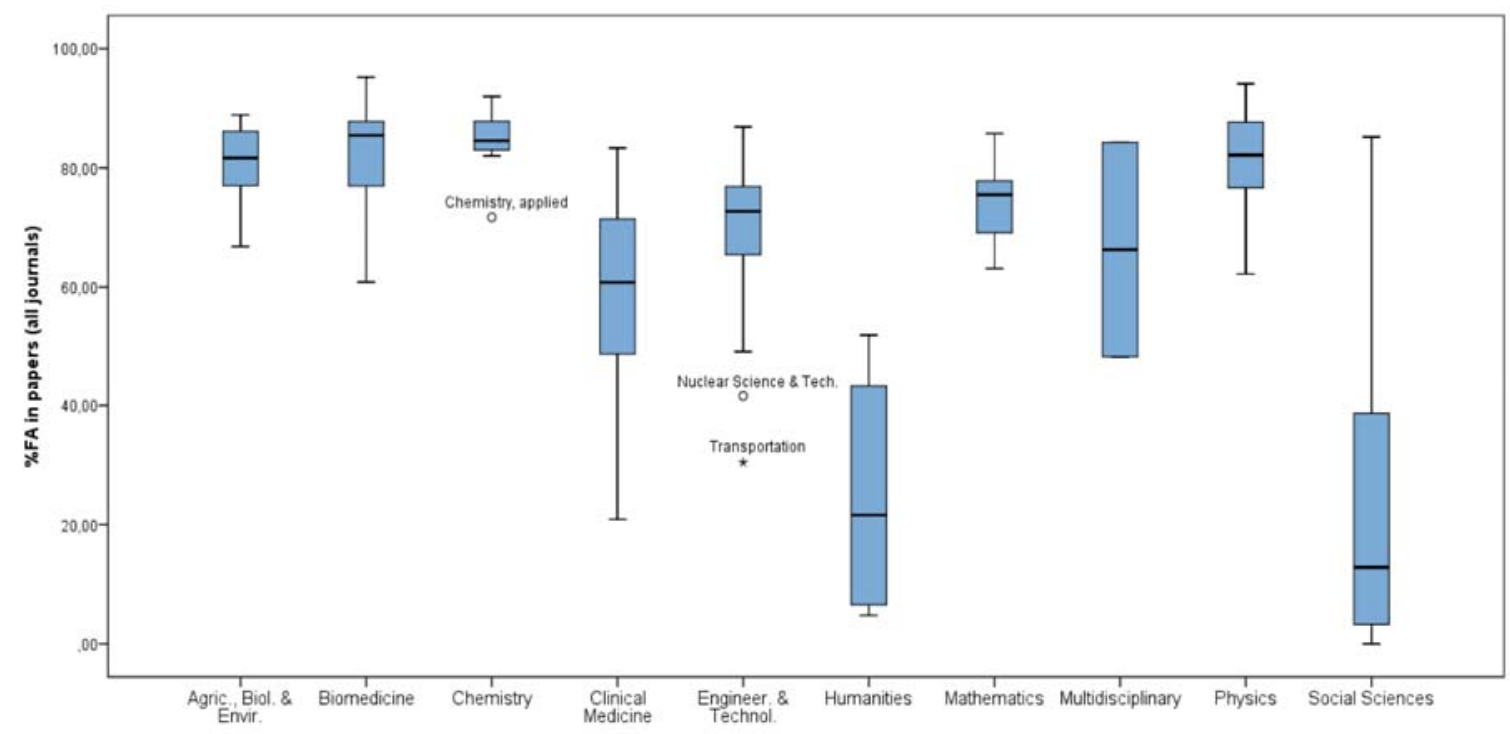

Note: Only subject categories with at least 30 papers are considered $(n=196)$.

Fig. 2. Distribution of the category share of papers with FA by subject area. 
This is a postprint version of: Díaz-Faes, A.A., \& Bordons, M. (2014). Acknowledgements in scientific publications: presence in Spanish science and text patterns across disciplines. Journal of the Association for

Information Science and Technology, 65 (9), 1834-1849. DOI: 10.1002/asi.23081.

The final publication is available at Wiley: http://onlinelibrary.wiley.com/doi/10.1002/asi.23081/abstract

\section{Influence of journal prestige}

Interestingly, the presence of FA in Q1 journals is higher than in the total set of journals ( $82 \%$ vs. $73 \%$ ). This applies to all subject areas, but the differences are especially significant in Humanities $^{5}$ (47\% of FA in Q1 journals vs. $20 \%$ in total journals) and Social Sciences (47\% vs. 28\%) (Table 4).

Table 4. Presence of FA by subject area.

\begin{tabular}{lrrr|rcc}
\hline \multirow{2}{*}{ Subject area } & \multicolumn{3}{c|}{ Total journals } & \multicolumn{3}{c}{ Q1 journals } \\
\cline { 2 - 7 } & \multicolumn{1}{c}{$\begin{array}{c}\text { No. } \\
\text { Papers }\end{array}$} & $\begin{array}{c}\text { No. Papers } \\
\text { with FA }\end{array}$ & $\begin{array}{c}\text { \% Papers } \\
\text { with FA }\end{array}$ & $\begin{array}{c}\text { No. } \\
\text { Papers }\end{array}$ & $\begin{array}{c}\text { No. Papers } \\
\text { with FA }\end{array}$ & $\begin{array}{c}\text { \% Papers } \\
\text { with FA }\end{array}$ \\
\hline Agric., Biol. \& Envir. & 7,974 & 6,473 & 81.1 & 4,907 & 4,172 & 85.0 \\
Biomedicine & 7,934 & 6,413 & 80.8 & 4,385 & 3,852 & 87.8 \\
Chemistry & 5,951 & 4,996 & 84.0 & 4,018 & 3,473 & 86.4 \\
Clinical Medicine & 7,609 & 4,525 & 59.4 & 3,969 & 2880 & 72.6 \\
Engineer. \& Technol. & 8,573 & 6,298 & 73.5 & 5,212 & 4,183 & 80.3 \\
Humanities & 356 & 72 & 20.2 & 74 & 35 & 47.3 \\
Mathematics & 2,220 & 1,695 & 76.4 & 931 & 764 & 82.1 \\
Multidisciplinary & 655 & 520 & 79.4 & 456 & 419 & 91.9 \\
Physics & 7,064 & 5,779 & 81.8 & 4,327 & 3,821 & 88.3 \\
Social Sciences & 2,882 & 805 & 27.8 & 1,143 & 542 & 47.4 \\
\hline Total & 38,257 & 27,774 & 72.6 & 21,058 & 17,209 & 81.7 \\
\hline
\end{tabular}

Note: The sum of publications exceeds the actual total because there are journals assigned to more than one area.

A high correlation is observed between the percentage of papers with FA in total journals and in the set of Q1 journals by subject area (Figure 3a). To explore to what extent there are differences by subject category within a given area, the percentage of papers with FA by category is also shown (Figure 3b) (colors are used to identify the subject categories in a given area). A strong and positive correlation is observed at both levels, subject areas $(\rho=0.82, \mathrm{p}<0.01)$ and subject categories $(\rho=0.91, \mathrm{p}<0.01)$. Most areas and categories are placed above the diagonal line in the graph (dashed line) which means that the percentage of FA in Q1 journals tends to be higher than in total journals. 
This is a postprint version of: Díaz-Faes, A.A., \& Bordons, M. (2014). Acknowledgements in scientific publications: presence in Spanish science and text patterns across disciplines. Journal of the Association for Information Science and Technology, 65 (9), 1834-1849. DOI: 10.1002/asi.23081.

The final publication is available at Wiley: http://onlinelibrary.wiley.com/doi/10.1002/asi.23081/abstract

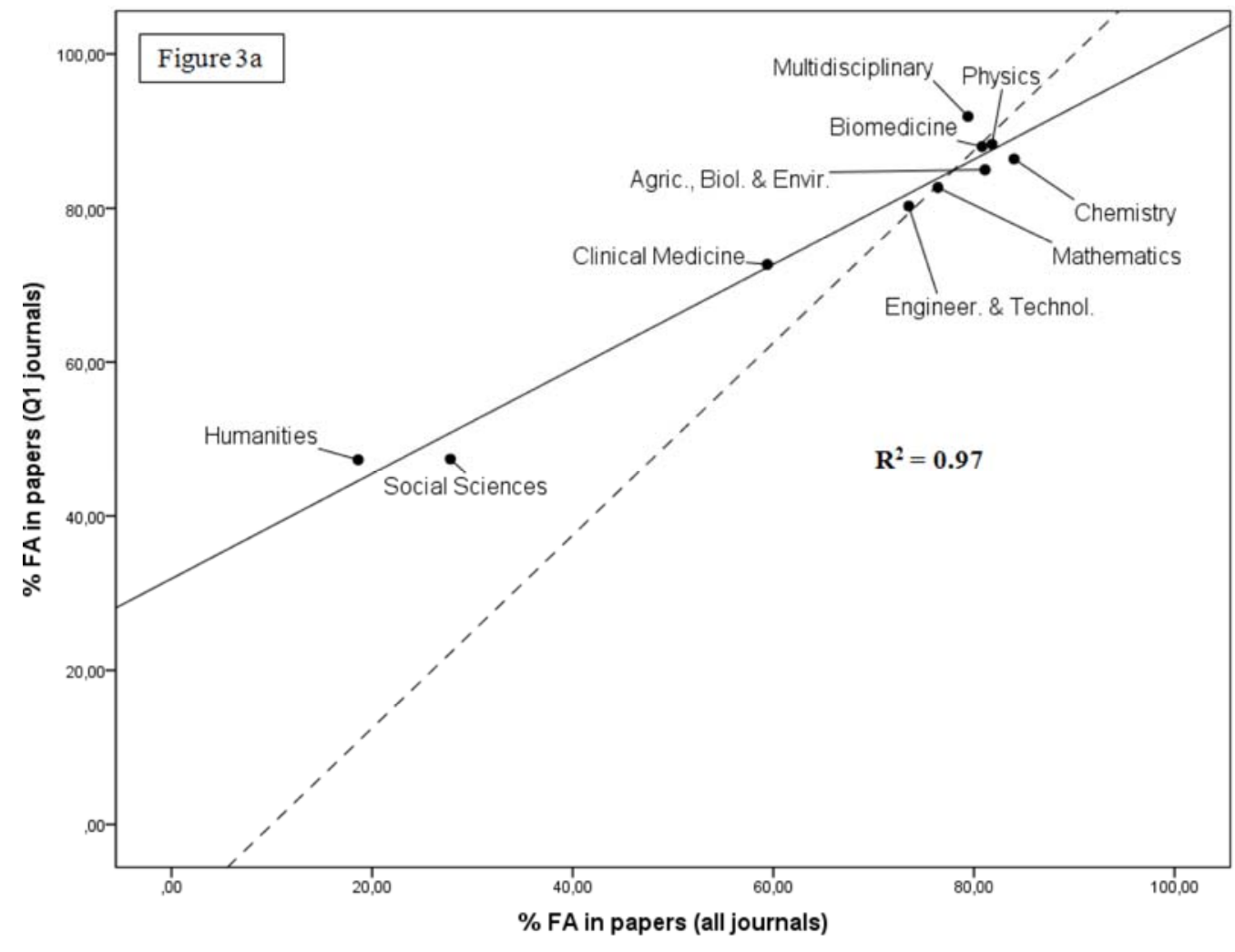


This is a postprint version of: Díaz-Faes, A.A., \& Bordons, M. (2014). Acknowledgements in scientific publications: presence in Spanish science and text patterns across disciplines. Journal of the Association for

Information Science and Technology, 65 (9), 1834-1849. DOI: 10.1002/asi.23081.

The final publication is available at Wiley: http://onlinelibrary.wiley.com/doi/10.1002/asi.23081/abstract

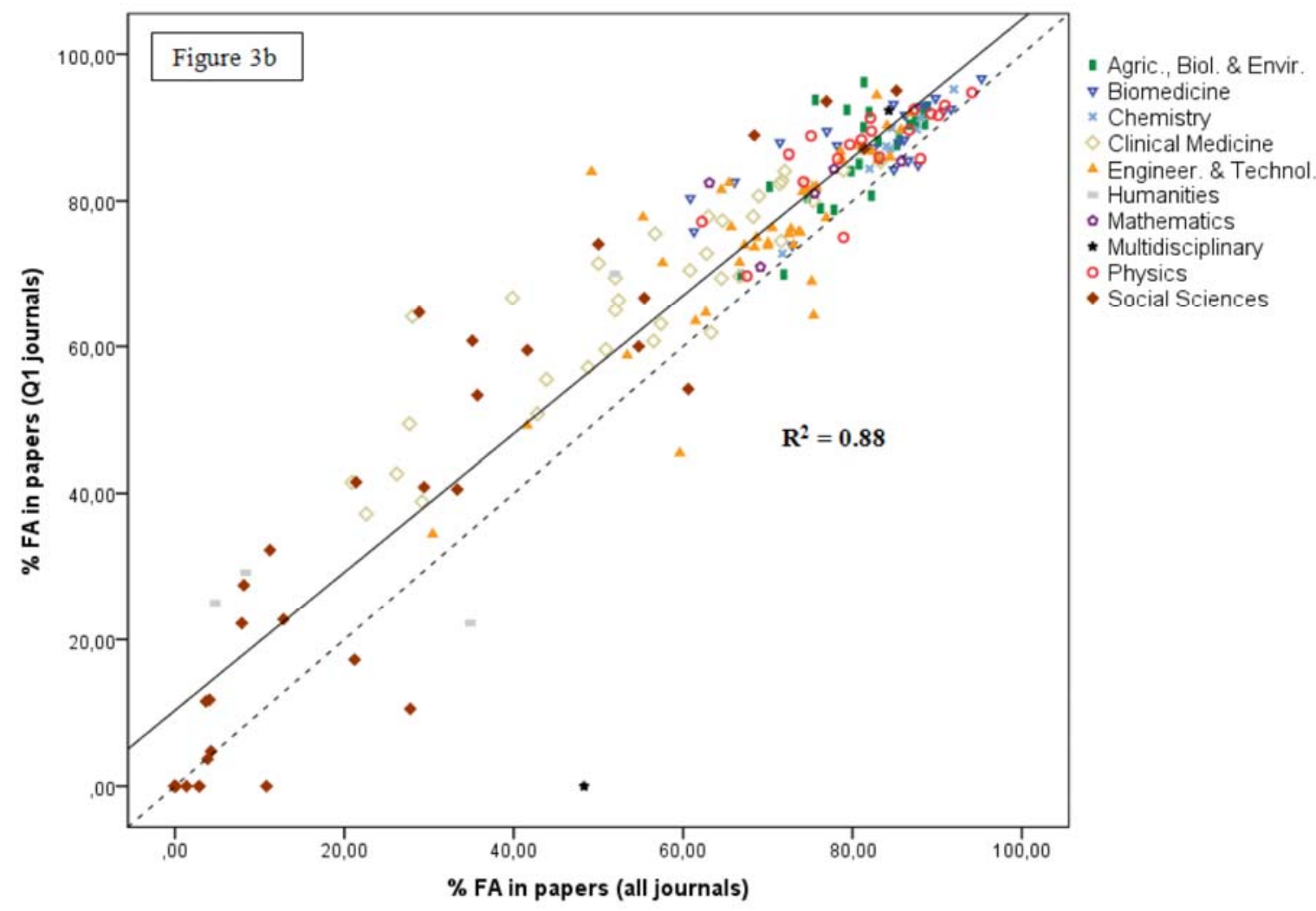

Notes: Only subject categories with at least 30 papers are shown in the scatter plot $(n=196)$.

The solid line represents the regression line. The dashed line represents the diagonal in the graph.

Fig. 3. Relationship between the percentage of papers with FA in total journals and in Q1 journals by subject area (3a) and subject category (3b).

We can see in Figure 3b that subject categories in a given subject area tend to group together. However, it is worth noting that the greatest scattering of categories is observed in Social Sciences and Clinical Medicine. A more detailed analysis of the Social Sciences area is shown in Figure 4, where the percentage of papers with FA in the total set of journals and in the subset of Q1 journals by subject category is shown (excluding those without FA). As mentioned above, FA is more likely to appear in Q1 journals, although their frequency varies largely by category. The areas which are closer to experimental sciences are more likely to include FA: see, for example, Psychology, Biological (95\%), Health Care Sciences \& Services (89\%) and Geography/Physical (87\%). Almost 
This is a postprint version of: Díaz-Faes, A.A., \& Bordons, M. (2014). Acknowledgements in scientific publications: presence in Spanish science and text patterns across disciplines. Journal of the Association for

Information Science and Technology, 65 (9), 1834-1849. DOI: 10.1002/asi.23081.

The final publication is available at Wiley: http://onlinelibrary.wiley.com/doi/10.1002/asi.23081/abstract

no FA presence is observed in other subject categories such as Psychology/Educational, Business, and History of Social Sciences. Inter-discipline differences with regard to the level of economic resources needed to conduct research can be a determining factor for FA presence.

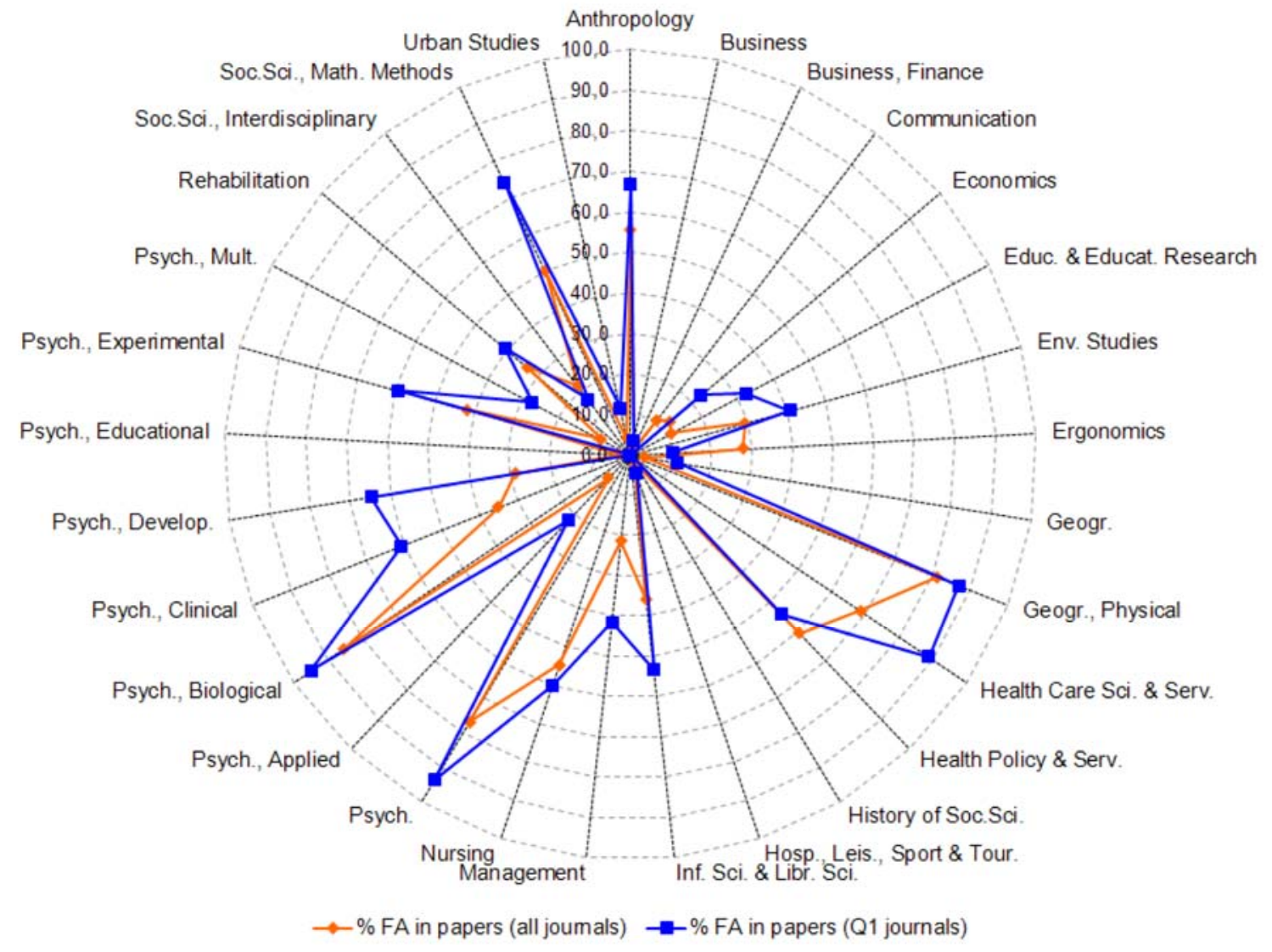

Note: Only subject categories with at least 30 papers are considered.

Fig. 4. FA presence in Social Sciences subject categories: total journals and Q1 journals.

\section{Influence of the number of authors}

The relationship between the number of authors per paper and the presence of the acknowledgement section is analyzed. Assuming that team size grows with the complexity of research, the need of infrastructures and the level of required economic support, FA presence is expected to increase with the number of authors per paper. Table 5 shows the average number of authors per paper by subject area depending on whether the FA section is present or not. The 
This is a postprint version of: Díaz-Faes, A.A., \& Bordons, M. (2014). Acknowledgements in scientific publications: presence in Spanish science and text patterns across disciplines. Journal of the Association for Information Science and Technology, 65 (9), 1834-1849. DOI: 10.1002/asi.23081.

The final publication is available at Wiley: http://onlinelibrary.wiley.com/doi/10.1002/asi.23081/abstract

average number of authors tends to be higher for the set of papers including FA, being the differences statistically significant in Engineering \& Technology, Clinical Medicine, Social Sciences, and Humanities (Mann-Whitney's U test, $\mathrm{p}<0.01$ ).

Table 5. Average number of authors related to the presence of FA by subject area.

\begin{tabular}{lccc}
\hline & \multicolumn{3}{c}{ No. authors/paper } \\
\cline { 2 - 3 } Subject area & \multicolumn{2}{c}{$M \pm S D$} & \\
\cline { 2 - 3 } & Without FA & With FA & -value \\
\hline Agric., Biol. \& Envir. & $5.0 \pm 1.6$ & $5.0 \pm 0.9$ & $\mathrm{NS}$ \\
Biomedicine & $6.0 \pm 1.3$ & $6.8 \pm 1.6$ & $\mathrm{NS}$ \\
Chemistry & $5.0 \pm 1.0$ & $5.1 \pm 0.4$ & $\mathrm{NS}$ \\
Clinical Medicine & $6.1 \pm 1.2$ & $8.3 \pm 2.2$ & $<0.01$ \\
Engineer. \& Technol. & $4.1 \pm 1.3$ & $5.2 \pm 4.4$ & $<0.01$ \\
Humanities & $1.6 \pm 0.8$ & $3.3 \pm 1.4$ & $<0.01$ \\
Mathematics & $2.8 \pm 0.3$ & $3.0 \pm 0.3$ & $\mathrm{NS}$ \\
Multidisciplinary & $6.4 \pm 5.0$ & $7.9 \pm 6.1$ & $\mathrm{NS}$ \\
Physics & $13.0 \pm 19.4$ & $14.5 \pm 19.7$ & $\mathrm{NS}$ \\
Social Sciences & $3.3 \pm 1.2$ & $5.1 \pm 2.8$ & $<0.01$ \\
\hline
\end{tabular}

The relationship between the number of authors per paper and FA frequency varies by subject area (Figure 5). It is worth noting that the share of papers with FA increases almost linearly with the number of authors in some areas such as Clinical Medicine, Social Sciences, and Humanities. In the remaining areas, the highest increase in FA presence is observed from 1-author to 2-author papers, showing a very small increase thereafter. The Multidisciplinary area shows a mixed pattern: an important surge in FA presence is observed from 1-author to 2-author papers, but FA increase progressively with the number of authors involved. 
This is a postprint version of: Díaz-Faes, A.A., \& Bordons, M. (2014). Acknowledgements in scientific publications: presence in Spanish science and text patterns across disciplines. Journal of the Association for Information Science and Technology, 65 (9), 1834-1849. DOI: 10.1002/asi.23081.

The final publication is available at Wiley: http://onlinelibrary.wiley.com/doi/10.1002/asi.23081/abstract

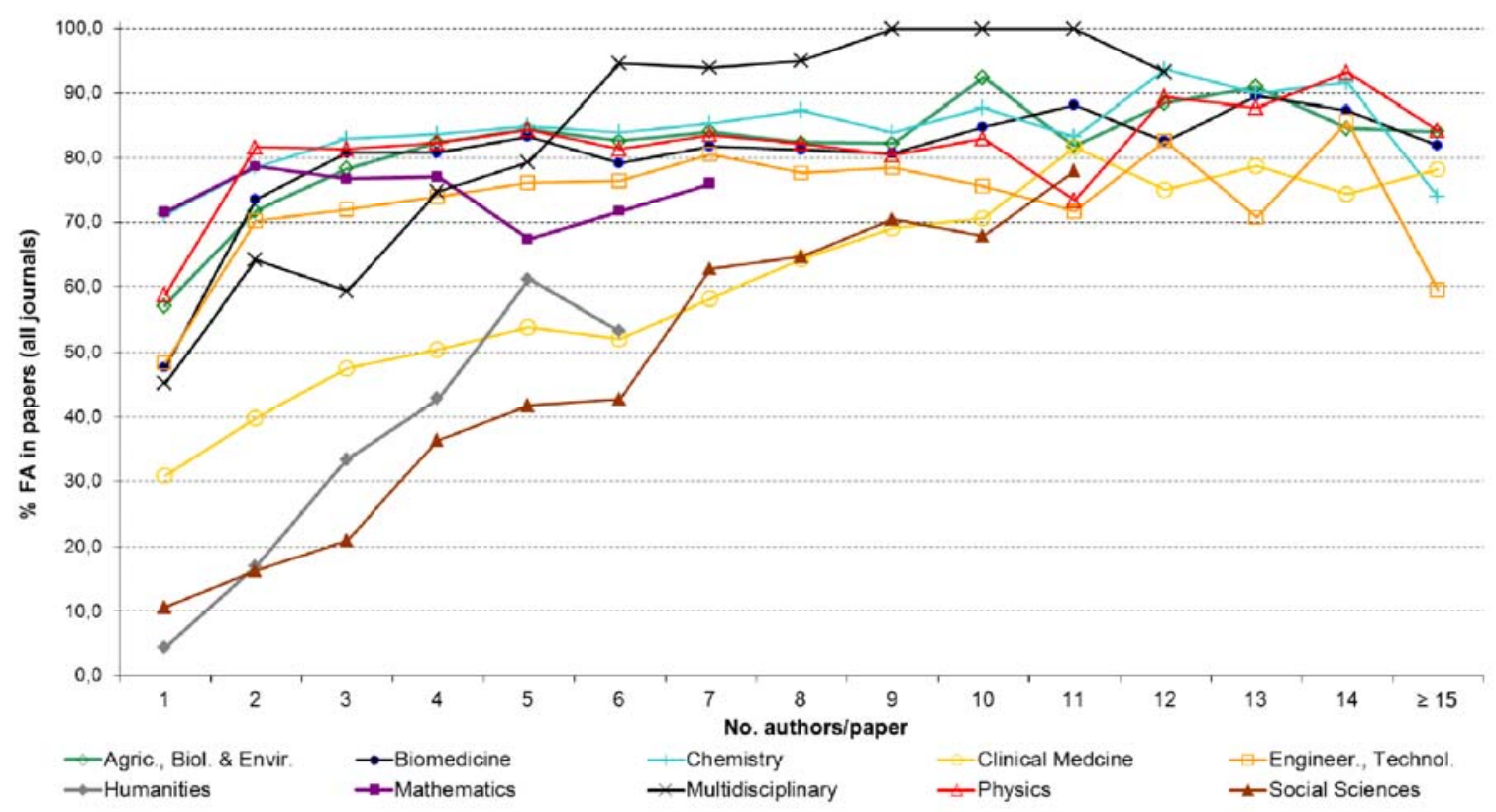

Fig. 5. Presence of FA by number of authors per paper and subject area.

\section{Influence of the research level}

On average, papers with FA tend to show a slightly higher basic research level than the rest of papers, although statistically significant differences are only observed in Clinical Medicine (Table 6).

Table 6. Average research level related to the presence of FA by subject area.

\begin{tabular}{lccc}
\hline \multirow{2}{*}{ Subject area } & \multicolumn{3}{c}{ Research level } \\
\cline { 2 - 3 } & \multicolumn{2}{c}{$M \pm S D$} & \multirow{2}{*}{-value } \\
\cline { 2 - 3 } & Without FA & With FA & \\
\hline Agric., Biol. \& Envir. & $2.9 \pm 0.8$ & $2.9 \pm 0.8$ & $\mathrm{NS}$ \\
Biomedicine & $3.2 \pm 0.4$ & $3.3 \pm 0.4$ & $\mathrm{NS}$ \\
Chemistry & $3.2 \pm 0.9$ & $3.3 \pm 0.9$ & $\mathrm{NS}$ \\
Clinical Medicine & $1.8 \pm 0.4$ & $2.1 \pm 0.5$ & $<0.01$ \\
Engineer. \& Technol. & $1.8 \pm 0.6$ & $2.0 \pm 0.5$ & $\mathrm{NS}$ \\
Mathematics & $2.6 \pm 0.7$ & $2.7 \pm 0.7$ & $\mathrm{NS}$ \\
Multidisciplinary & $2.5 \pm 1.1$ & $2.9 \pm 1.3$ & $\mathrm{NS}$ \\
Physics & $3.3 \pm 0.5$ & $3.4 \pm 0.5$ & $\mathrm{NS}$ \\
Social Sciences & $1.7 \pm 0.8$ & $2.1 \pm 0.9$ & $\mathrm{NS}$ \\
\hline
\end{tabular}

Note: Humanities journals are not shown because the research level is only calculated for SCI and SSCI journals. 
This is a postprint version of: Díaz-Faes, A.A., \& Bordons, M. (2014). Acknowledgements in scientific publications: presence in Spanish science and text patterns across disciplines. Journal of the Association for Information Science and Technology, 65 (9), 1834-1849. DOI: 10.1002/asi.23081.

The final publication is available at Wiley: http://onlinelibrary.wiley.com/doi/10.1002/asi.23081/abstract

\section{b) Analysis of textual patterns by subject category}

A textual data analysis of the FA section was carried out for 1,491 papers published in the four selected subject categories. These categories differ dramatically in their FA presence: it ranges from $12.8 \%$ in Economics to $88.5 \%$ in Evolutionary Biology (Table 2). In our study, the entire corpus comprises 50,710 word occurrences ("running words"), of which 10,936 are different forms ("types") (Table 7). Hapax legomena (that are those words with only one occurrence in the corpus) total 7,124 (14\% of running words; $65 \%$ of types). It is important to note that although the semantic richness of the acknowledgements is not very high due to the specific role of this section in the papers, the number of hapax legomena is high because of references to projects and persons.

Table 7. Lexical features of the corpus.

\begin{tabular}{l|cccc|c}
\hline & $\begin{array}{c}\text { Cardiac \& } \\
\text { Cardiovascular } \\
\text { Systems }\end{array}$ & Economics & $\begin{array}{c}\text { Evolutionary } \\
\text { Biology }\end{array}$ & $\begin{array}{c}\text { Statistics } \\
\& \\
\text { Probability }\end{array}$ & Corpus \\
\hline No. Running words & 11,609 & 4,734 & 23,600 & 10,767 & 50,710 \\
No. Types & 2,436 & 1,351 & 5,104 & 2,045 & 10,936 \\
Max. Word frequency & 605 & 344 & 1,287 & 755 & 2,991 \\
No. of hapax legomena & 1,509 & 844 & 3,456 & 1,315 & 7,124 \\
\hline
\end{tabular}

CA was applied to the lexical table we obtained, which is a cross tabulation including word occurrences for each of the four subject categories. The first two axes retain $92.9 \%$ of all the information contained in the lexical table.

Relative contributions of the factor to the element for the columns (Table 8) show that Axis 1 is determined by the Cardiac \& Cardiovascular Systems subject category, whereas Axis 2 is configured by the rest of categories, Statistics \& Probability being its leading contributor. As regards the rows, words related to economic issues present the highest contributions (consultant, fee, employee, honorary) in Axis 1, while Axis 2 is characterized by words that reflect some type of 
This is a postprint version of: Díaz-Faes, A.A., \& Bordons, M. (2014). Acknowledgements in scientific publications: presence in Spanish science and text patterns across disciplines. Journal of the Association for Information Science and Technology, 65 (9), 1834-1849. DOI: 10.1002/asi.23081.

The final publication is available at Wiley: http://onlinelibrary.wiley.com/doi/10.1002/asi.23081/abstract

contribution (analysis, collect, assistance, technical).

Table 8. Relative contributions of the factor to the element for subject categories.

\begin{tabular}{lccc}
\hline Subject categories & Axis 1 & Axis 2 & Axis 3 \\
\hline Statistics \& Probability & 47 & $\mathbf{8 1 3}$ & 139 \\
Cardiac \& Cardiovascular Systems & $\mathbf{9 9 2}$ & 7 & 1 \\
Economics & 120 & $\mathbf{5 3 7}$ & $\mathbf{3 4 3}$ \\
Evolutionary Biology & $\mathbf{3 7 4}$ & $\mathbf{6 2 6}$ & 0 \\
\hline
\end{tabular}

CA results shown in Figure 6 reveal differences in the lexical patterns of the subject categories selected. Economics and Statistics \& Probability are found close to each other in the first quadrant of the spatial plot suggesting that they present similar lexical profiles and similar acknowledgement patterns. Evolutionary Biology stands in the fourth quadrant because it is characterized by different words. These subject categories are close in the projection to Axis 2 which is characterized by words denoting some type of contribution, support or process involving technical or research work. Conversely, Cardio \& Cardiovascular System is located in the third quadrant close to Axis 1, where some words about grants and economics present a high level of contributions. 
This is a postprint version of: Díaz-Faes, A.A., \& Bordons, M. (2014). Acknowledgements in scientific publications: presence in Spanish science and text patterns across disciplines. Journal of the Association for Information Science and Technology, 65 (9), 1834-1849. DOI: 10.1002/asi.23081.

The final publication is available at Wiley: http://onlinelibrary.wiley.com/doi/10.1002/asi.23081/abstract

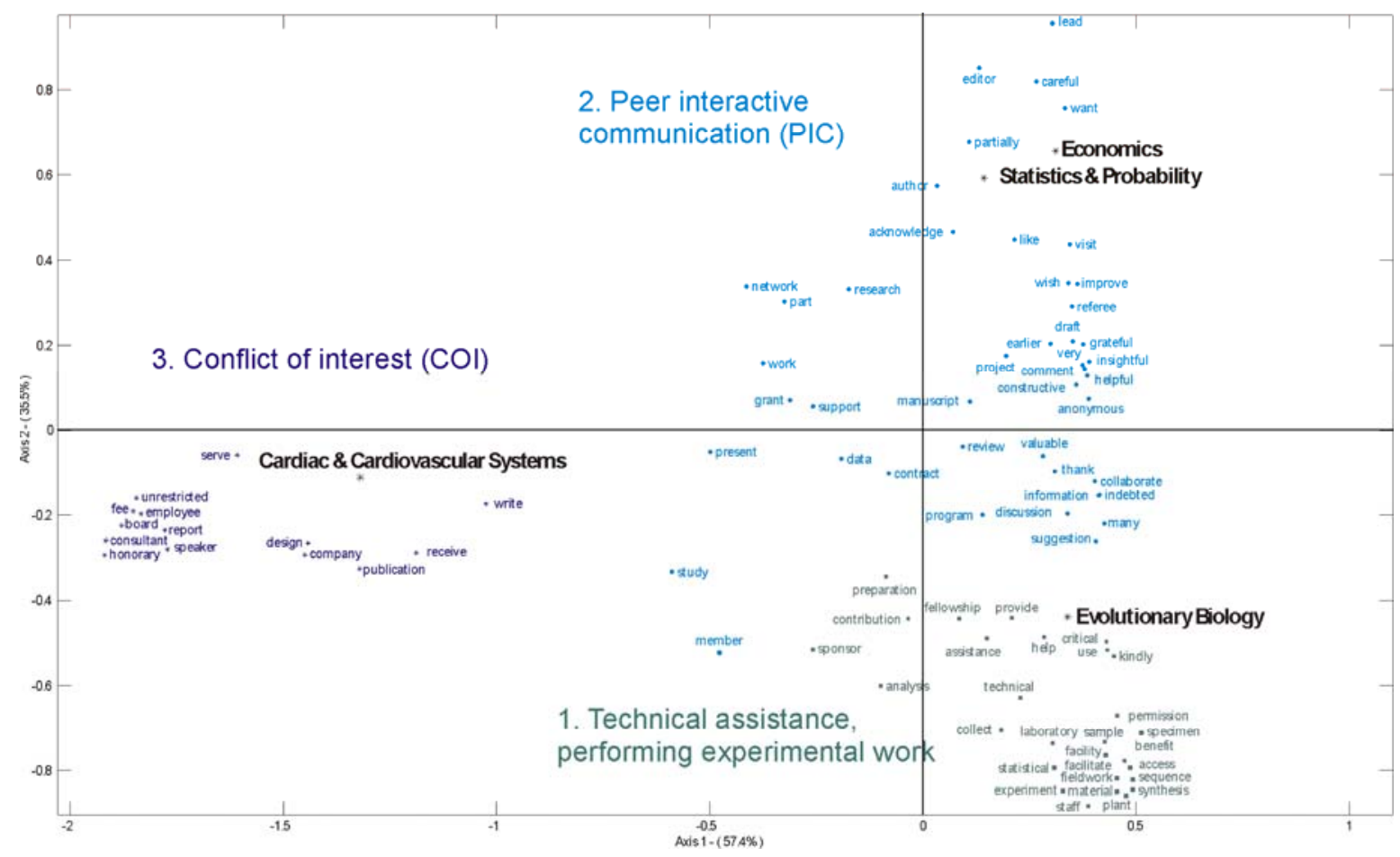

Fig. 6. CA representation of the different clusters obtained on the principal factorial plane 1-2.

Ward's Hierarchical Clustering method using factor scores was applied to describe the pattern of the different subject categories, which includes both funding and sub-authorship collaboration data (Figure 6). Quality of representation is over $93 \%$ in plane 1-2 for clusters detected. Three clusters have been identified according to the lexical features of the corpus:

- Cluster 1 is formed by words which reveal gratitude for allowing access to facilities, assistance in sample collection, statistical analysis or laboratory work. These contributions can be defined as technical assistance and performing experimental work. It is the pattern found in Evolutionary Biology.

- Cluster 2 recognizes some intellectual debt which contributes to improve the quality of research. It includes words such as comment, improve, draft, insightful, helpful, careful, anonymous and referee and reflects cognitive, moral and editorial support received by the authors, i.e., the "peer interactive communication" concept (PIC) introduced by McCain 
This is a postprint version of: Díaz-Faes, A.A., \& Bordons, M. (2014). Acknowledgements in scientific publications: presence in Spanish science and text patterns across disciplines. Journal of the Association for Information Science and Technology, 65 (9), 1834-1849. DOI: 10.1002/asi.23081.

The final publication is available at Wiley: http://onlinelibrary.wiley.com/doi/10.1002/asi.23081/abstract

(1991). This is the pattern described for Economics and Statistics \& Probability.

- Cluster 3 is formed by words which reveal an existing concern about potential conflicts of interest in the conduct and publication of research. It includes words, such as honorary, fees and consultants, in relation to the collaboration between academic scientists and industry. This is the pattern described in Cardiac \& Cardiovascular Systems, which is a clinical discipline which differs completely from the rest of categories analyzed in the nature of the information recorded in the acknowledgement section of papers.

\section{Discussion}

Our study analyses acknowledgements in the English-written scientific publications of Spain-based researchers in WoS in 2010 and confirms the existence of differences in FA presence by subject area, genre, journal prestige and -in a specific area- by the basic/applied nature of research. Moreover, text mining and multivariate analysis have proved useful in discovering inter-field differences in the patterns of FA based on similar lexical profiles. Several discipline features such as their theoretical/experimental nature, the need for economic support, the relevance of teamwork and the dependence on complex facilities contribute to build differentiated patterns of acknowledgements.

An FA section was present in approximately $73 \%$ of the publications written in English by Spain-based researchers in 2010, which is a higher rate than that found for Spanish publications in previous studies (Costas \& van Leeuwen, 2012 and Wang et al., 2012). A number of methodological factors, such as the language and genre of the studied papers, may contribute to explain these differences. On the one hand, the fact that only papers written in English are taken into account in our study may contribute to explain the higher values of FA presence observed, since weaker funding acknowledgement rates have been found for papers written in other languages in the literature (Salager-Meyer et al., 2009). On the other hand, our study focuses on 
This is a postprint version of: Díaz-Faes, A.A., \& Bordons, M. (2014). Acknowledgements in scientific publications: presence in Spanish science and text patterns across disciplines. Journal of the Association for Information Science and Technology, 65 (9), 1834-1849. DOI: 10.1002/asi.23081.

The final publication is available at Wiley: http://onlinelibrary.wiley.com/doi/10.1002/asi.23081/abstract

articles and reviews, while studies including other genres such as editorials or letters, which very rarely contain acknowledgements, are likely to reveal a lower presence of FA (Costas \& van Leeuwen, 2012).

Moreover, there is an additional factor that should be borne in mind. When trying to explore potential differences in FA presence between papers written in English and in other languages by Spain-based researchers, we observed than funding acknowledgements were not recorded at all by the WoS for the set of papers not written in English. After submitting a query to Thomson Reuters, we verified that acknowledgements need to be in English to be captured and processed by the WoS. This observation has important implications since papers written in other languages could be considered as non-funded, although the fact is that we have no information on this issue. Accordingly, the rate of non-funded papers could be overestimated in those studies in which all papers (not only papers written in English) are considered. This can be especially significant in the more locally-oriented areas, such as Social Sciences or Clinical Medicine, where the share of papers in languages other than English is higher.

In any case, it is interesting to point out that FA presence in Spanish publications was above world average in 2009 in the study of Costas and van Leeuwen (2012), where Spain held fifth position (after P.R. China, Sweden, South Korea and Finland) in the world rank of top FA frequency countries. The existence of mandatory regulations of explicit mention of funding agencies has been argued to explain a high share of acknowledged papers in some countries (Costas \& van Leeuwen, 2012), Spain being one of them (BOE, 2008). The fact that FA is more likely to appear in articles than in reviews was also observed by Costas and van Leeuwen (2012) and Salager-Meyer et al. (2011). It is clear that articles including original research require more collaboration and infrastructure than reviews which usually consist on a revision of previous research on a specific topic. On the other hand, the low presence of FA in proceedings papers may be due to the fact that they tend to be shorter and to contain less 
This is a postprint version of: Díaz-Faes, A.A., \& Bordons, M. (2014). Acknowledgements in scientific publications: presence in Spanish science and text patterns across disciplines. Journal of the Association for Information Science and Technology, 65 (9), 1834-1849. DOI: 10.1002/asi.23081.

The final publication is available at Wiley: http://onlinelibrary.wiley.com/doi/10.1002/asi.23081/abstract

detailed information than articles (González-Albo, Moreno, Morillo, \& Bordons, 2012).

\section{Funding acknowledgement by subject area}

Our study reveals important differences in FA presence by area. The lowest values of FA are found in Humanities and Social Sciences and the highest in experimental fields, such as Chemistry and Physics, these results being consistent with previous studies (Cronin et al., 2003, 2004; Costas \& van Leeuwen, 2012). The theoretical/experimental nature of research and its technical complexity which may require sophisticated infrastructures and teamwork are joint factors determining the field's dependence on economic resources and, therefore, FA presence too. The low share of FA in Humanities and Social Sciences could also be influenced by cultural factors since the inclusion of formal acknowledgements in papers is a more widely established tradition in experimental fields (Costas \& van Leeuwen, 2012).

The higher presence of FA described for the more basic fields in a previous study (Costas \& van Leeuwen, 2012) is supported by our results, since Engineering \& Technology and Clinical Medicine are the areas with the highest applied research level and the lowest FA rate (apart from Social Sciences). We do not know to what extent this is due to the higher dependence of basic research on extramural funding or to the different sources of funding used by basic and clinical research in their acknowledgement policies. In any case, within any given area, significant differences in the research level of funded vs. non-funded papers were only observed in the case of Clinical Medicine, where funded papers present a more basic level maybe because research more clearly oriented to clinical practice is more likely to be developed with intramural resources which are not specifically acknowledged.

\section{Funding acknowledgement by journal prestige}

An interesting finding in our study is the higher presence of FA in high impact factor 
This is a postprint version of: Díaz-Faes, A.A., \& Bordons, M. (2014). Acknowledgements in scientific publications: presence in Spanish science and text patterns across disciplines. Journal of the Association for Information Science and Technology, 65 (9), 1834-1849. DOI: 10.1002/asi.23081.

The final publication is available at Wiley: http://onlinelibrary.wiley.com/doi/10.1002/asi.23081/abstract

journals (Q1), which suggests the higher quality of funded research. Among the possible underlying reasons for this, we can mention the more stringent peer review process applied to funded research or the fact that funding allows scientists to allocate more time to research, access better technology or collaborate with more qualified scientists (Zhao, 2010). Publications with FA were also published in higher impact factor journals in the study of Costas and van Leeuwen (2012), where they obtained a higher citation rate than non-funded publications. A higher citation rate for publications with FA has also been described elsewhere (Lewison \& Dawson, 1998; Zhao, 2010; Levitt, 2011). Although a positive relationship between the number of funding sources and the citation impact of papers has been suggested in the literature (Lewison \& Dawson, 1998; Rigby, 2011), Rigby concludes in a recent study that the effect of the number of funding acknowledgements is weak and that it should not be considered a reliable indicator of research impact (Rigby 2013). On the other hand, Zhao (2010) advocates a cautious approach since some of the most cited papers include no funding acknowledgements (Zhao, 2010). Unfortunately, citation data were not analyzed in our study and, therefore, we cannot provide any new evidence on this issue.

In our study, the biggest difference in FA presence between total and Q1 journals is observed in Humanities, Social Sciences and Clinical Medicine, in that order. These areas show the lowest share of papers with FA, but FA presence reveals its highest increase if only high impact factor journals are considered (Q1 journals). We could argue that research in these areas is more locally-oriented (Archambault, Vignola-Gagne, Cote, Lariviere, \& Gingras, 2006; González-Alcaide, Valderrama-Zurián, \& Aleixandre-Benavent, 2012), and maybe funding is more frequently associated to the more international research topics within each area, which are more easily placed in top-rank journals. However, a deeper analysis of data would be required to confirm this hypothesis.

Since national journals are rarely placed in the first quartile of the impact factor journal 
This is a postprint version of: Díaz-Faes, A.A., \& Bordons, M. (2014). Acknowledgements in scientific publications: presence in Spanish science and text patterns across disciplines. Journal of the Association for Information Science and Technology, 65 (9), 1834-1849. DOI: 10.1002/asi.23081.

The final publication is available at Wiley: http://onlinelibrary.wiley.com/doi/10.1002/asi.23081/abstract

ranking within their disciplines a high volume of publications in them might contribute to explain the lower FA presence in the total set of papers as compared to the Q1 set. However, the share of papers in Spanish journals is very low in this study, since only English-written papers have been considered (it accounts for $2 \%$ of papers; ranging from $0.1 \%$ of papers in Chemistry to $7 \%$ in Social Sciences and $12 \%$ in Humanities). In any case, the study of potential differences between national and international journals in FA presence remains an interesting topic for further research. A lower presence of FA in non-English journals has been described in the literature (Salager-Meyer et al., 2009), where it was attributed to a less strict commitment to comply with international authorship guidelines. Thus, scientists would be more easily considered authors in detriment of acknowledges, maybe because the acknowledgement section has not yet become an institutionalized practice in some contexts. To what extent this applies for journals published in Spain and whether there are differences according to their language remain as open questions. However, for the time being it cannot be addressed through the WoS database because acknowledgement data are not recorded for Spanish-written journals.

\section{Funding acknowledgement by number of authors}

In our study, a higher number of authors per paper are observed in papers with FA as compared to those without FA. Different interrelated factors may contribute to explain this tendency. On the one hand, this may be due to the fact that more complex research requiring more infrastructures and teamwork is more likely to be funded because it cannot be conducted without economic support. On the other hand, it should be mentioned that scientists in Spain are encouraged to team together when they apply for research grants from the most important agencies as a means to foster team consolidation in the country, so that larger teams may stand a better chance in their quest for funding. The fact that collaborative research may be favored by funding agencies has been previously suggested in the literature (for example, Zhao 2010). 
This is a postprint version of: Díaz-Faes, A.A., \& Bordons, M. (2014). Acknowledgements in scientific publications: presence in Spanish science and text patterns across disciplines. Journal of the Association for Information Science and Technology, 65 (9), 1834-1849. DOI: 10.1002/asi.23081.

The final publication is available at Wiley: http://onlinelibrary.wiley.com/doi/10.1002/asi.23081/abstract

Finally, it is interesting to point out that a higher number of authors per paper of funded research could be an influential factor on the final quality of the papers and contribute to explain why they are more often found in Q1 journals, since a positive relationship between the number of authors and the impact of research has been formerly described in the literature (Gazni \& Didegah 2011; Bordons, Aparicio \& Costas, 2012).

Besides, it should be noted that in most subject areas the highest increase in FA presence is observed when we move from single-authored to multi-authored papers, since the former are less likely to receive funding and that such research is supposed to be less dependent on infrastructure. The situation is somewhat different in the areas of Social Sciences, Humanities and Clinical Medicine, which show the lowest overall FA presence although it tends to increase linearly with the number of authors. In the first two areas, single-authored papers represent an important share of research and funding may have a critical role to boost collaboration and multi-authored papers. In the case of Clinical Medicine, many papers might have been written by physicians as a result of their professional practice at medical sites with no special extramural funding, and yet as the number of authors increases so does the probability of having extramural funding, especially for larger teams which may be involved in clinical studies frequently supported by commercial companies.

\section{Acknowledgement patterns by subject category}

Despite the fact that only four categories are studied, the existence of inter-field differences in the textual pattern of the acknowledgements is confirmed by this paper and different functions played by acknowledgements depending on the field have been identified. These differences are mainly dependent on the type of research, but other influences — both at the local and global levels — such as social and cultural factors also play a role.

Our study shows that PIC is a characteristic feature of the more theoretical or social- 
This is a postprint version of: Díaz-Faes, A.A., \& Bordons, M. (2014). Acknowledgements in scientific publications: presence in Spanish science and text patterns across disciplines. Journal of the Association for Information Science and Technology, 65 (9), 1834-1849. DOI: 10.1002/asi.23081.

The final publication is available at Wiley: http://onlinelibrary.wiley.com/doi/10.1002/asi.23081/abstract

oriented fields (i.e., Statistics \& Probability and Economics), while the recognition of technical aid (data collection and analysis) is more common in experimental research (i.e., Evolutionary Biology) and the mention of potential conflicts of interest occurs especially in the clinical fields (i.e., Cardiac \& Cardiovascular Systems). With regard to "sub-authorship information", PIC acknowledgements are particularly relevant, since they imply an intellectual debt and —as has been pointed out by other authors (McCain, 1991; Davis \& Cronin, 1993) — suggest an extra "peer-review" process before publication which may enhance the quality of the final paper (Costas \& van Leeuwen, 2012). The recognition of technical work is also important, since it can prove essential for the development of experimental research in specific fields. Finally, the acknowledgement pattern described for the clinical field is not so clearly related to subauthorship information since it mainly deals with potential personal or financial relationships (i.e., with commercial firms) that may bias the authors' research and compromise the credibility of their publications.

Conflicts of interest related to project support are becoming ever more common in clinical medicine, since scientists may receive funding from commercial firms and private foundations which may interfere with their ability to analyze data independently, prepare, and publish the results. As a consequence, leading journals request authors to disclose the potential financial interests of sponsors and to describe their involvement in the research project, where appropriate. Although financial conflicts of interest may lead to biased research publications, a close relationship between the academic and the industrial sectors is beneficial for research (Stossel, 2012) and the disclosure of information on potential conflicts of interest contributes to strengthen article credibility and public confidence in research.

What emerges from our study is that the contents of the acknowledgement section vary largely by subject category and can contain very heterogeneous data. As the research process gains in complexity (increasing role of teams and network-based research, diversity of funding 
This is a postprint version of: Díaz-Faes, A.A., \& Bordons, M. (2014). Acknowledgements in scientific publications: presence in Spanish science and text patterns across disciplines. Journal of the Association for Information Science and Technology, 65 (9), 1834-1849. DOI: 10.1002/asi.23081.

The final publication is available at Wiley: http://onlinelibrary.wiley.com/doi/10.1002/asi.23081/abstract

sources, more sophisticated administrative and legal frameworks, growing concern about ethical issues), so does the amount and typology of the information included in the acknowledgement section too. Separating funding data, conflict of interest statements and other type of acknowledgements (e.g., sub-authorship) is becoming the norm in some journals (Lancet, 2011; Nature, 2012) and may contribute to facilitate the task of authors when submitting papers, the flow of information to readers and its study by interested scientists.

\section{Authors, subauthors and contributors}

The textual analysis of the FA section reveals acknowledgement patterns by discipline which are determined by both funding information and sub-authorship collaboration in science. Although our main interest was to identify acknowledgement patterns rather than specific collaborators, it is clear that subauthors providing technical and/or intellectual assistance to the research lie behind these patterns.

At this stage of the discussion, there emerges the interesting issue of trying to sort out to what extent there is a clear delimitation between the kinds of contributions that deserve to be listed as co-authorship and those falling in the sub-authorship category. Different guidelines most of them from journal editors - describe the qualifying criteria for authorship, but these are not universally accepted (Claxton, 2005). According to the guidelines of the International Committee of Medical Journal Editors (ICMJE, 2013), to be mentioned as an author, a scientist should not only make substantial contributions to the conception and design of the study or to the acquisition, analysis and interpretation of data, but also participate in drafting the article or revising it critically, as well as in the approval of its final version. Collaborators who do not fully comply with authorship criteria should be acknowledged (Claxton, 2005), but there are plenty of signs suggesting that researchers are scarcely familiar with authorship criteria (Marusic, Bosnjak, \& Jeroncic, 2011), which, in addition, may vary from one discipline, 
This is a postprint version of: Díaz-Faes, A.A., \& Bordons, M. (2014). Acknowledgements in scientific publications: presence in Spanish science and text patterns across disciplines. Journal of the Association for Information Science and Technology, 65 (9), 1834-1849. DOI: 10.1002/asi.23081.

The final publication is available at Wiley: http://onlinelibrary.wiley.com/doi/10.1002/asi.23081/abstract

institution or team to another. Although most author guidelines tend to privilege the creative and intellectual aspects of research over technical contributions, the interest of the latter is being increasingly recognized by scientists themselves (Winston, 1985; Hunt, 1991; Vinkler, 1993; Digiusto, 1994) and by journal editors (Wager, 2009). Indeed, the key issue is not only to decide "what type of contribution" (PIC, technical, etc.) deserves authorship, but also "what threshold of involvement" is required.

The need to clarify the specific role of every author in a given piece of research has led some journals (see for example, Nature ${ }^{6}$ ) to include a list of contributors —instead of authorsin their papers, where the contribution of each author to the research is explicitly stated, thus blurring the differences between "authors" and "subauthors". The contributorship system would open up new prospects for research in the field of collaboration issues in science but, although the ICMJE encourages journals to include contributor lists in their papers, only $10 \%$ of the biomedical journals had adopted the system by 2009 (Wager, 2009). In the meantime, the study of the acknowledgement section is an interesting option for an in-depth analysis of collaborative research practices, assuming that a sizeable part of them remains beyond the scope from the classical bibliometric indicators used to measure research collaboration, since these are mainly based on co-authorship analyses (Laudel, 2002) and are inadequate for the provision of a full and thorough image of collaboration in science.

\section{Limitations of the study}

In this study, the analysis of sub-authorship patterns is restricted to papers which present funding information, since only in those cases the acknowledgement section of papers is captured by the WoS. This is a limitation derived from the indexing policy of the WoS but, since funding support is acknowledged in a large number of papers included in our study (73\%), we consider that the analysis of discipline patterns may yield reliable results. 
This is a postprint version of: Díaz-Faes, A.A., \& Bordons, M. (2014). Acknowledgements in scientific publications: presence in Spanish science and text patterns across disciplines. Journal of the Association for Information Science and Technology, 65 (9), 1834-1849. DOI: 10.1002/asi.23081.

The final publication is available at Wiley: http://onlinelibrary.wiley.com/doi/10.1002/asi.23081/abstract

The presence of acknowledgements in papers may be influenced by different factors such as the fact that it is not always mandatory in scientific journals — differences by field do exist; that all funding bodies may not be equally interested in having their support disclosed commercial organizations may be reluctant to be mentioned for strategic reasons (Rigby, 2011) — ; and that authors may differ in their propensity to acknowledge their influences and the assistance received. Although these limitations should be borne in mind, we consider that this study provides an interesting insight on the presence and role played by acknowledgements in the English-written scientific output of a non-Anglophone country with a particular focus on inter-field differences and sub-authorship information.

\section{Conclusions and future research}

Our study confirms the existence of differences in FA presence by subject area, genre, journal prestige, co-authorship, and - in a specific area - the basic/applied type of research. Moreover, inter-field differences in the nature of acknowledgements which go beyond financial support and include sub-authorship information are detected in the four subject categories under analysis. Extending the study to other research fields would allow us to categorize fields according to their acknowledgement patterns. Physics remains an attractive field for future research and, in particular, big science disciplines due to their specifics with regard to the contribution of infrastructures to the development of large collaborative experiments which may be acknowledged in papers.

Moreover, this study opens up new avenues for future research. The comparative study of the presence of funded research in papers written in English against papers written in other languages is an interesting topic for further analysis, which has been only addressed at the level of specific journals in the literature (Salager-Meyer et al., 2009). On the other hand, multivariate analysis could be useful to delve into the relationships between acknowledgement presence and 
This is a postprint version of: Díaz-Faes, A.A., \& Bordons, M. (2014). Acknowledgements in scientific publications: presence in Spanish science and text patterns across disciplines. Journal of the Association for Information Science and Technology, 65 (9), 1834-1849. DOI: 10.1002/asi.23081.

The final publication is available at Wiley: http://onlinelibrary.wiley.com/doi/10.1002/asi.23081/abstract

different features of research such as collaboration, research level, and impact of research. The inclusion of citations received by papers along with the impact of publication journals would be desirable.

Certain developments in the way the acknowledgement information is included in the WoS may enhance future research on the topic. First and foremost, the collection of funding acknowledgement data for all journals, regardless of their language, would be desirable. Secondly, the inclusion of the acknowledgement section in all WoS records — and not only when funding is acknowledged - would allow more global, comprehensive and accurate studies. Finally, a better structuring of the acknowledgement information, including, for example, pre-established field subsections (in both journals and databases) (as previously suggested by other authors, e.g., Cronin \& Weaver, 1995), would allow us to discriminate between different types of information (i.e., financial data, conflict of interest disclosure, subauthorship information) and facilitate automatic data processing. Nowadays, there is a growing interest in the study of the acknowledgement section of papers because as the research process grows in complexity, so does too the amount and type of information included in the acknowledgements, revealing some of the particularities of research in each discipline.

\section{Acknowledgements}

This research was supported by the Spanish Ministry of Science and Innovation (CSO2008-06310) and the Spanish National Research Council (JAE predoctoral grant). We are very thankful to Javier Aparicio and Ignacio Santabárbara for their valuable assistance in data management as well as to Isabel Gómez and Purificación Galindo for their comments on a draft of this paper. Special thanks to two anonymous referees for their useful suggestions which have contributed significantly to improve the original manuscript. 
This is a postprint version of: Díaz-Faes, A.A., \& Bordons, M. (2014). Acknowledgements in scientific publications: presence in Spanish science and text patterns across disciplines. Journal of the Association for Information Science and Technology, 65 (9), 1834-1849. DOI: 10.1002/asi.23081.

The final publication is available at Wiley: http://onlinelibrary.wiley.com/doi/10.1002/asi.23081/abstract

\section{References}

Archambault, E., Vignola-Gagne, E., Cote, G., Lariviere, V., \& Gingras, Y. (2006). Benchmarking scientific output in the social sciences and humanities: The limits of existing databases. Scientometrics, 68(3), 329-342.

Benzécri, J.P. (1973). L’Analyse de Données. Vol. 2. L'analyse des correspondances. Paris: Dunod.

Berthier, F., \& Bouroche, J.R. (1975). Analyse des données multidimensionnelles. Paris: Presses Universitaires de France.

Boletin Oficial del Estado (2008). Orden Pre/621/2008, por la que se regulan las bases, el régimen de ayudas y la gestión de la línea instrumental de actuación de proyectos de $\mathrm{I}+\mathrm{D}+\mathrm{i}$, en el marco del Plan Nacional de Investigación Científica, Desarrollo e Innovación Tecnológica, 2008-2011. BOE num.59, 8 March 2008, pp.14, 217. <http://www.boe.es/boe/dias/2008/03/08/pdfs/A1420514219.pdf> Accessed: 22/03/13.

Bolasco S. (1992). Sur différentes stratégies dans une analyse des formes textuelles: Une expérimentation à partir de données d'enquête, Jornades Internacionals d'Analisi de Dades Textuals (pp. 69-88). Barcelona: UPC.

Bordons, M., Aparicio, J., \& Costas, R. (2012). Heterogeneity of collaboration and its relationship with research impact in a biomedical field. Scientometrics, doi: 0.1007/s11192-012-0890-7.

Bordons, M., \& Gómez, I. (2000). Collaboration networks in science. In B. Cronin \& H.B. Atkins, (Eds.), The web of knowledge: A Festschrift in honor of Eugene Garfield (pp. 197-213). Medford, NJ: Information Today, Inc. \& ASIS.

Costas, R., \& van Leeuwen, T.N. (2012). Approaching the "reward triangle": general analysis of the presence of funding acknowledgements and "peer interactive communication" in scientific publications. Journal of the American Society for Information Science and Technology, 63(8), 16471661.

Claxton, L.D. (2005). Scientific authorship part 2. History, recurring issues, practices, and guidelines. Mutation Research, 589, 31-45.

Cronin, B. (1991). Let credits roll: a preliminary examination of the role played by mentors and trusted 
This is a postprint version of: Díaz-Faes, A.A., \& Bordons, M. (2014). Acknowledgements in scientific publications: presence in Spanish science and text patterns across disciplines. Journal of the Association for Information Science and Technology, 65 (9), 1834-1849. DOI: 10.1002/asi.23081.

The final publication is available at Wiley: http://onlinelibrary.wiley.com/doi/10.1002/asi.23081/abstract

assessors in disciplinary formation. Journal of Documentation, 47(3), 227-239.

Cronin, B. (1995) The scholar's courtesy: The role of acknowledgements in the primary communication process. Los Angeles: Taylor Graham.

Cronin, B., McKenzie, G., \& Rubio, L. (1993). The norms of acknowledgement in four humanities and social sciences disciplines. Journal of Documentation, 49(1), 29-43.

Cronin, B., McKenzie, G., \& Stiffer, M. (1992). Patterns of acknowledgement. Journal of Documentation, 48(2), 107-122.

Cronin, B., McKenzie, G., Rubio, L., \& Weaver-Wozniak, S. (1993). Accounting for influence: acknowledgments in Contemporary Sociology. Journal of the American Society for Information Science, 44(7), 406-412.

Cronin, B., Shaw, D., \& La Barre, K. (2003). A cast of thousands: co-authorship and sub-authorship collaboration in the $20^{\text {th }}$ century as manifested in the scholarly literature of psychology and philosophy. Journal of the American Society for Information Science and Technology, 54(9), 855871.

Cronin, B., Shaw, D., \& La Barre, K. (2004). Visible, less visible, and invisible work: patterns of collaboration in 20th century Chemistry. Journal of the American Society for Information Science and Technology, 55(2), 160-168.

Cronin, B., \& Weaver, S. (1995). The praxis of acknowledgement: from bibliometrics to influmetrics. Revista Española de Documentación Científica, 18(2), 172-177.

Davis, C.H., \& Cronin, B. (1993). Acknowledgements and intellectual indebtedness: a bibliometric conjecture. Journal of the American Society for Information Science and Technology, 44(10), 590592.

Digiusto, E. (1994). Equity in authorship: a strategy for assigning credit when publishing. Social Science \& Medicine, 38, 55-58.

Edge, D. (1979). Quantitative measures of communications in science: a critical review. History of Science, 17, 102-134.

Escofier, B., \& Pagès, J. (1992). Análisis factoriales simples y múltiples. Objetivos, métodos e 
This is a postprint version of: Díaz-Faes, A.A., \& Bordons, M. (2014). Acknowledgements in scientific publications: presence in Spanish science and text patterns across disciplines. Journal of the Association for Information Science and Technology, 65 (9), 1834-1849. DOI: 10.1002/asi.23081.

The final publication is available at Wiley: http://onlinelibrary.wiley.com/doi/10.1002/asi.23081/abstract

interpretación. Bilbao, Spain: University of Basque Country.

Gazni, A., \& Didegah, F. (2011). Investigating different types of research collaboration and citation impact: a case study of Harvard University’s publications. Scientometrics, 87(2) 251-265.

Giles, C.L., \& Council, I.G. (2004). Who gets acknowledged: measuring scientific contributions through automatic acknowledgement indexing. Proceedings of the National Academy of Sciences of the United States of America, 101(51), 17599-17604.

Gillet, R. (1991). Pitfalls in Assessing Research Performance by Grant Income. Scientometrics, 22, 253263.

González-Albo, B., Moreno, L., Morillo, F., \& Bordons, M. (2012). Bibliometric indicators for the analysis of the research performance of a multidisciplinary institution: the CSIC. Revista Española de Documentación Cientifica, 35(1), 9-37.

González-Alcaide, G., Valderrama-Zurián, J.C., \& Aleixandre-Benavent, R. (2012). The impact factor in non-English speaking countries. Scientometrics, 92(2), 297-311.

Heffner, A.G. (1981). Funded research, multiple authorship, and subauthorship collaboration in four disciplines. Scientometrics, 3(1), 5-12.

Hunt, R. (1991) Trying an authorship index. Nature, 352(18), 187.

ICMJE. (2013). Uniform Requirements for Manuscripts Submitted to Biomedical Journals: Ethical Considerations in the Conduct and Reporting of Research: Authorship and Contributorship. <http://www.icmje.org/ethical_1author.html> Accessed: 04/02/13.

Kassirer, J.P., \& Angell, M.A. (1991). On authorship and acknowledgements. The New England Journal of Medicine, 325(21), 1510-1521.

Lamalle, C., Martínez, W., Fleury, S., \& Salem, A. (2003). Lexico 3. Université de la Sorbonne nouvelle, Paris. <http://www.tal.univ-paris3.fr/lexico/>.

Lancet (2011). Information for authors. <http://download.thelancet.com/flatcontentassets/authors/lancetinformation-for-authors.pdf $>$. Accessed: 01/03/13.

Laudel, G. (2002). Collaboration and reward. What do we measure by co-authorships? Research Evaluation, 11(1), 3-15. 
This is a postprint version of: Díaz-Faes, A.A., \& Bordons, M. (2014). Acknowledgements in scientific publications: presence in Spanish science and text patterns across disciplines. Journal of the Association for Information Science and Technology, 65 (9), 1834-1849. DOI: 10.1002/asi.23081.

The final publication is available at Wiley: http://onlinelibrary.wiley.com/doi/10.1002/asi.23081/abstract

Lebart, L., \& Salem, A. (1994). Statistique textuelle. Paris: Dunod.

Lebart, L., \& Salem, A., Bécue, M. (2000). Análisis estadístico de textos. Lleida (España): Milenio.

Levitt, J.M. (2011). Are funded articles more highly cited than unfunded articles? A preliminary investigation. Proceedings of ISSI 2011: The 13th Conference of the International Society for Scientometrics and Informetrics (pp.1013-1015). Durban: ISSI.

Lewison, G., \& Dawson, G. (1998). The effect of funding on the outputs of biomedical research. Scientometrics, 41(1-2), 17-27.

Lewison, G., \& Markusova, V. (2010). The evaluation of Russian cancer research. Research Evaluation $19(2), 129-144$.

Marusic, A., Bosnjak, L., \& Jeroncic, A. (2011). A systematic review of research on the meaning, ethics and practices of authorship across scholarly disciplines. Plos One, 6(9), 1-17.

McCain, K.W. (1991). Communication, competition, and secrecy: the production and dissemination of research-related information in genetics. Sciences, Technology \& Human Values, 16(4), 491-516.

Melin, G., \& Persson, O. (1996). Studying research collaboration using co-authorships. Scientometrics $36(3), 363-377$.

Narin, F., Pinski, G., \& Gee, H.H. (1976). Structure of the biomedical literature. JASIS, 27(1), 25-44.

Nature (2012). Guide to publication policies of the Nature journals. $<$ http://www.nature.com/authors/gta.pdf $>$. Accessed: 01/03/13.

Noma, E. (1986). Subject Classification and influence weights for 3000 journals. Research report under CHI and NIH contracts. New Jersey: Computer Horizons Inc. Research.

Patel, N. (1973). Collaboration in the professional growth of American Sociology. Social Science Information, 12(6), 77-92.

Rigby, J. (2011). Systematic Grant and funding body acknowledgement data for Publications: new dimensions and new controversies for research policy and evaluation. Research Evaluation, 20(5), $365-375$.

Rigby, J. (2013). Looking for the impact of peer review: does count of funding acknowledgements really predict research impact? Scientometrics, 94, 57-73. 
This is a postprint version of: Díaz-Faes, A.A., \& Bordons, M. (2014). Acknowledgements in scientific publications: presence in Spanish science and text patterns across disciplines. Journal of the Association for Information Science and Technology, 65 (9), 1834-1849. DOI: 10.1002/asi.23081.

The final publication is available at Wiley: http://onlinelibrary.wiley.com/doi/10.1002/asi.23081/abstract

Salager-Meyer, F., Alcaraz-Ariza, M.A., Luzardo-Briceño, M., \& Jabbour, G. (2011). Scholarly gratitude in five geographical contexts: a diachronic and cross-generic approach of the acknowledgment paratext in medical discourse (1950-2010). Scientometrics, 86, 763-784.

Salager-Meyer, F., Alcaraz-Ariza, M.A., \& Pabón-Bervesí, M. (2009). "Backstage solidarity” in Spanish and English-written medical research papers. Publication context and the acknowledgement paratext. Journal of the American Society for Information Science and Technology, 60(2), 307-317.

Stossel, T.P. (2012). What's wrong with COI? The Scientist. <http://thescientist.com/2012/06/12/opinion-whats-wrong-with-coi/> Accessed: 20/12/12.

Thomson. <http://wokinfo.com/products_tools/multidisciplinary/webofscience/fundingsearch/>

Vicente-Villardón, J.L. (2010). MultBiplot: A package for Multivariate Analysis using Biplots. Departamento de Estadística. Universidad de Salamanca. <http://biplot.usal.es/ClassicalBiplot/index. html>.

Vinkler, P. (1993). Research contribution, authorship and team cooperativeness. Scientometrics, 26(1), 213-230.

Wager, E. (2009). Recognition, reward and responsibility: Why the authorship of scientific papers matters. Maturitas, 62(2), 109-112.

Wang, X., Liu, D., Ding, K., \& Wang, X. (2012). Science funding and research output: a study on 10 countries. Scientometrics, 91(2), 591-599.

Wang, J., \& Shapira, P. (2011). Funding acknowledgement analysis: an enhanced tool to investigate research sponsorship impacts: the case of nanotechnology. Scientometrics, 87, 563-586.

Winston, R.B. (1985). A suggested procedure for determining order of authorship in research publications. Journal of Counseling and Development, 63(8), 55-518.

Zhao, D.Z. (2010). Characteristics and impact of grant-funded research: a case study of the library and information science field. Scientometrics, 84, 293-306.

\footnotetext{
${ }^{1}$ Information provided by the Technical Support Team of Thomson Reuters, June 2013.
} 
This is a postprint version of: Díaz-Faes, A.A., \& Bordons, M. (2014). Acknowledgements in scientific publications: presence in Spanish science and text patterns across disciplines. Journal of the Association for Information Science and Technology, 65 (9), 1834-1849. DOI: 10.1002/asi.23081.

The final publication is available at Wiley: http://onlinelibrary.wiley.com/doi/10.1002/asi.23081/abstract

\footnotetext{
${ }^{2} \mathrm{http}$ //wokinfo.com/products_tools/multidisciplinary/webofscience/fundingsearch/

${ }^{3}$ In 2010, there were no English-written publications by Spanish authors in seven WoS subject categories.

${ }^{4}$ The "proceedings paper" genre refers to articles which have been previously presented in a conference. The two genres ("article" and "proceedings paper") are assigned to these papers by Thomson Reuters.

${ }^{5}$ It should be noted that the impact factor is not calculated by Thomson Reuters for journals only included in Arts \& Humanities. It is only available for some journals also included in the SSCI.

${ }^{6} \mathrm{http}: / /$ www.nature.com/nature/authors/gta/
} 